\title{
A Survey on AI-Driven Digital Twins in Industry 4.0: Smart Manufacturing and Advanced Robotics
}

 \\ 1 Laboratory for Machine Tools and Production Engineering (WZL), RWTH Aachen University, \\ D-52074 Aachen, Germany; m.fey@wzl.rwth-aachen.de (M.F.); c.brecher@wzl.rwth-aachen.de (C.B.) \\ 2 UBTECH North America Research and Development Center, Pasadena, CA 91101-4858, USA \\ 3 Department of Statistics, University of California Los Angeles, Los Angeles, CA 90095-1554, USA; \\ jiayi.li@g.ucla.edu \\ * Correspondence: z.huang@wzl.rwth-aachen.de (Z.H.); yangshen@ieee.org (Y.S.) \\ + These authors contributed equally to this work.
}

Citation: Huang, Z.; Shen, Y.; Li, J.; Fey, M.; Brecher, C. AI-Driven Digital Twins. Sensors 2021, 21, 6340. https://doi.org/10.3390/s21196340

Received: 15 July 2021

Accepted: 10 September 2021

Published: 23 September 2021

Publisher's Note: MDPI stays neutral with regard to jurisdictional claims in published maps and institutional affiliations.

\begin{abstract}
Digital twin (DT) and artificial intelligence (AI) technologies have grown rapidly in recent years and are considered by both academia and industry to be key enablers for Industry 4.0. As a digital replica of a physical entity, the basis of DT is the infrastructure and data, the core is the algorithm and model, and the application is the software and service. The grounding of DT and AI in industrial sectors is even more dependent on the systematic and in-depth integration of domainspecific expertise. This survey comprehensively reviews over 300 manuscripts on AI-driven DT technologies of Industry 4.0 used over the past five years and summarizes their general developments and the current state of AI-integration in the fields of smart manufacturing and advanced robotics. These cover conventional sophisticated metal machining and industrial automation as well as emerging techniques, such as 3D printing and human-robot interaction/cooperation. Furthermore, advantages of AI-driven DTs in the context of sustainable development are elaborated. Practical challenges and development prospects of AI-driven DTs are discussed with a respective focus on different levels. A route for AI-integration in multiscale/fidelity DTs with multiscale/fidelity data sources in Industry 4.0 is outlined.
\end{abstract}

Keywords: artificial intelligence; machine learning; deep learning; digital twin; digital shadow; Industry 4.0; sustainability; sustainable smart manufacturing; robotics; review

\section{Introduction}

Industry 4.0 and smart manufacturing are crucial fundamentals of modern industry and the national economy. Industry 4.0 aims to construct a universal networked architecture that addresses the interoperability and compatibility issues within and across all levels of the automation systems and factories, thus improving the flexibility and agility of conventional manufacturing. Equally indispensable to smart manufacturing is advanced robotics, which serves as an intelligent agent appearing in every corner of production lines. With the profound research and development of Industry 4.0 and artificial intelligence (AI), digital twin (DT) has drawn growing research attention [1-4]. As a digital replica of a physical entity, the basis of DT is the infrastructure and data, the core is the algorithm and model, and the application is the software and service. In recent years, the progressive aggravation of environmental problems, such as carbon emission and nuclear pollution, has required national industries to shift from conventional extensive economic growth to sustainable development. Achieving holistic sustainability commonly requires a balance within the financial, environmental, social and governance dimensions, i.e., FESG factors [5]. This increases the costs of manufacturing enterprises and simultaneously raises severe challenges for their organizations and processes. Against this backdrop, AI-powered DT technology is expected to adapt the traditional model-based approaches to the evolving 
boundary conditions and provide a demand-oriented, real-time capable evaluation basis to efficiently support decision making in multi-objective problems. There is already much research that discusses and characterizes DT from the view of general concepts and technologies [1,6-11] as well as certain fields, without targeted focus on AI, this novel enabler, i.e., product design [12,13], modeling and simulation [14], fault diagnostics and prognostics [15]. Practically, different engineering application scenarios have separate challenges and concerns. The grounding of DT and AI is even more dependent on the systematic and in-depth integration of domain-specific expertise. Currently, there is still a lack of comprehensive industry-oriented review of "AI + DT" technologies in the context of sustainability and circular economy. To further contribute to developing and landing of these general-purpose technologies (GPT) in smart manufacturing and advanced robotics, the following research questions $(\mathrm{RQ})$ are proposed in conducting this survey:

RQ1: What are the current research and concrete case solutions on DTs?

RQ2: What is the current state of AI integration in DTs in the above two areas?

RQ3: What are the benefits of AI-enabled DTs, considering sustainability?

RQ4: What are the challenges in practice and future work with AI-enabled DTs?

This paper endeavors to address this research gap by revisiting current developments on DTs from a domain-specific perspective, analyzing implemented AI methods in each subarea, sorting out the role they play in sustainable development, and summarizing practical challenges in various application fields. The following contributions are delivered in this study:

1. The general development and application cases with common AI methods in AI-driven DTs of Industry 4.0 are concluded.

2. The advantages of AI-driven DTs in sustainable development are elaborated regarding the FESG factors, which enable a quantitative assessment of sustainability.

3. Challenges and development prospects of AI-driven DTs in smart manufacturing and advanced robotics are discussed with a respective focus on different levels.

4. A route for AI-integration in multiscale/fidelity DTs with multiscale/fidelity data sources along the product lifecycle is outlined.

\subsection{Topic Definitions \\ 1.1.1. Digital Twin}

The concept of DT was described by the National Aeronautics and Space Administration (NASA) as a multiphysics, multiscale, probabilistic simulation that uses physical models, sensor updates, fleet history, etc., to mirror the life of its twin [16]. Later, DT was indicated by Grieves and Vickers as a dynamic model based on massive amounts of information and computing capability that change over the lifecycle, including creation, production, operations and disposal [17]. Based on the architecture in [18], Tao et al. proposed an extended five-dimension DT model, comprising a physical entity, a virtual entity, service, data and connection [15].

\subsubsection{Digital Shadow}

The concept "digital shadow" was mainly advocated by the German Academic Society for Production Engineering (WGP), whereby it is understood to be the sufficiently accurate representation of the processes in production, development and adjacent areas with the aim of generating a real-time capable evaluation basis of all relevant data [19]. Compared with the DT, a digital shadow does not require a high-resolution database, but a complete one [20]. Together with all of its subsystems, the digital shadow is designed as an information system or a multi-perspective information model to allow a more efficient operation of value creation systems, and is thus considered an enabler for data analytics in product lifecycle management (PLM) [21,22]. 


\subsubsection{Digital Thread}

The concept of "digital thread" was initially proposed by the U.S. Air Force as a framework to merge detailed design models with model-based systems engineering (MBSE) conceptual and top-level architectural models [23]. This idea was further driven by the National Institute of Standards and Technology (NIST) with the purpose of exchanging information, including product design and quality and equipment performance and health, across the product lifecycle [24]. A single digital thread is, thus, created with the modelbased ensemble of data in design, manufacturing, and inspection, which enables fullprocess traceability in a seamless, real-time, collaborative development among the project participants [25].

\subsection{Topic Delimitation and Coverage}

This survey provides in-depth insight into the current progress of AI-driven DT technologies, including the three aforementioned concepts, in Industry 4.0. Although there are various interpretations of the connotations and extensions of the DT, they share the same philosophy, namely, how to utilize digital replicas with near real-time capabilities to effectively enhance traditional organizations and processes across the product lifecycle, thereby improving industry competitiveness and optimizing resource allocation. Correspondingly, 5G communication and Internet of Things (IoT) technologies as well as standalone machine learning (ML) technologies without digital replicas are not the focus here. Over 300 manuscripts are covered on this basis.

\subsection{Paper Organization}

As illustrated in Figure 1, the rest of the review paper is organized as follows. In Section 2, we analyze the digital production twins toward sustainable resilient manufacturing at three different levels; in Section 3, we discuss the applications of DT in robots and human-robot interaction/human-robot collaboration. After dissecting AI-enabled case studies and branch-specific challenges of the development and deployment of DTs in industry verticals, Section 4 compares AI methods horizontally; Section 5 concludes the contributions of this paper and addresses the future work.

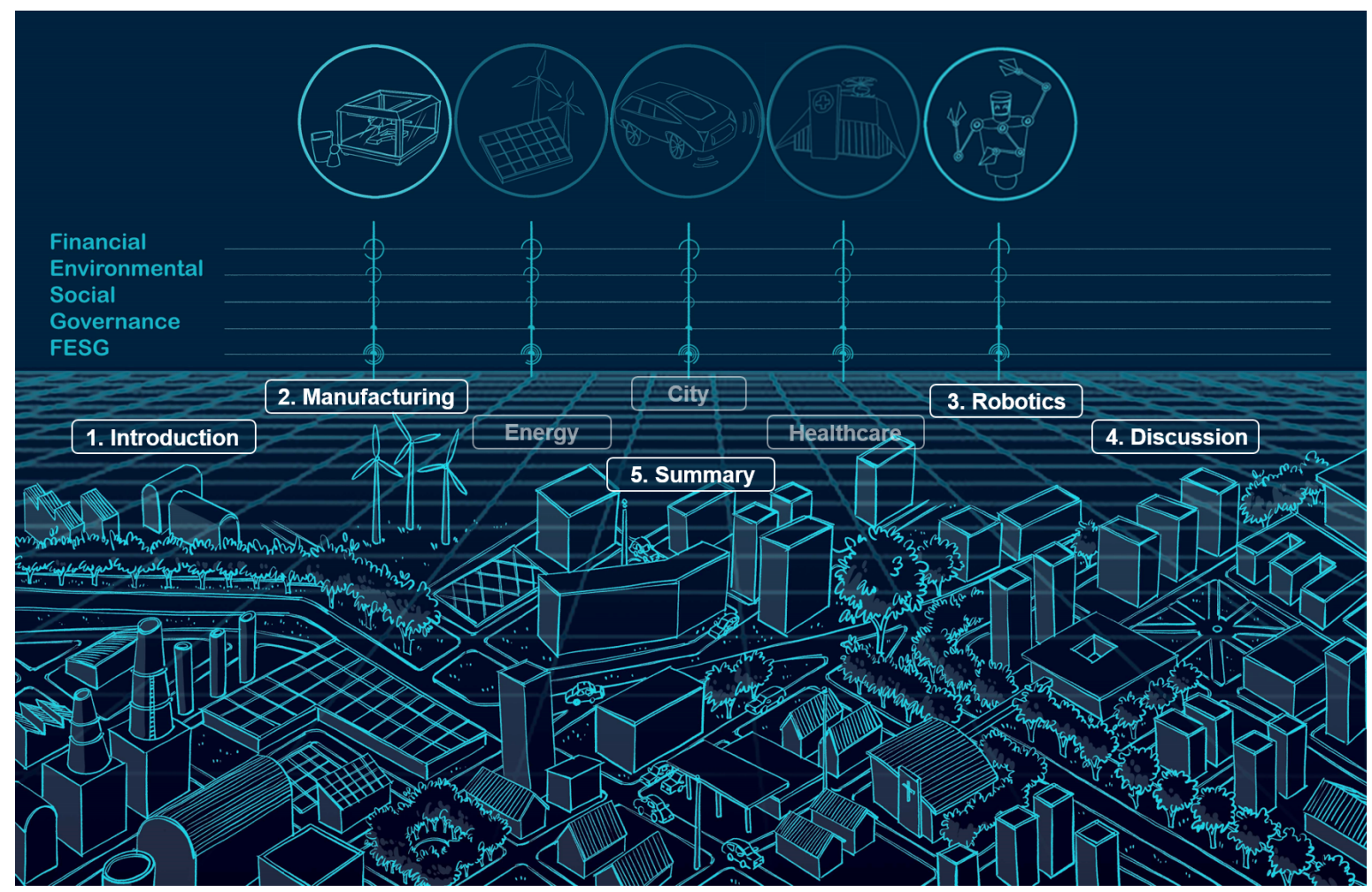

Figure 1. Overview of the review. 


\section{Sustainable Resilient Manufacturing}

\subsection{Overview}

The core task of manufacturing industry lies in producing qualitative products in a productive and available manner. Balancing these partially competing objectives under time-varying boundary conditions is becoming a challenge in the course of ever-shortened decision-making horizons [26]. In recent years, intensive research has been conducted in the areas of Industry 4.0 [27], cyber-physical production systems [28,29], and integrative production techniques [30] to address the VUCA (volatile, uncertain, complex, ambiguous) market environment. The widespread application of simulation models and ubiquitous connectivity provide a solid foundation for building digital production twin throughout the product lifecycle, which is considered a key enabler for future manufacturing transformation and upgrading in the era of big data [1,31,32]. In the context of the circular economy and sustainability pledges (e.g., European Green Deal), traditional resource-intensive productivity thinking is being replaced by a future vision of a more ecologically minded society, namely "sustainable productivity" [33]. This understanding of productivity incorporates FESG factors as a novel indicator for quantitatively assessing sustainable production as well as the performance (with tangible and intangible services as well as business models) and value creation systems (consisting of resource, process, and organization) of manufacturing companies, thus pushing them to embrace the required sustainability transformation, as illustrated in Figure 2. Various research of DTs, including general developments and AI-integrated cases, in terms of enhancing the trilemma of productivity, availability, and quality (financial) toward sustainable resilient manufacturing (environmental, social, governance) are discussed in the following three levels: factory and shop floor (Section 2.2), machinery and equipment (Section 2.3), as well as process and material (Section 2.4).

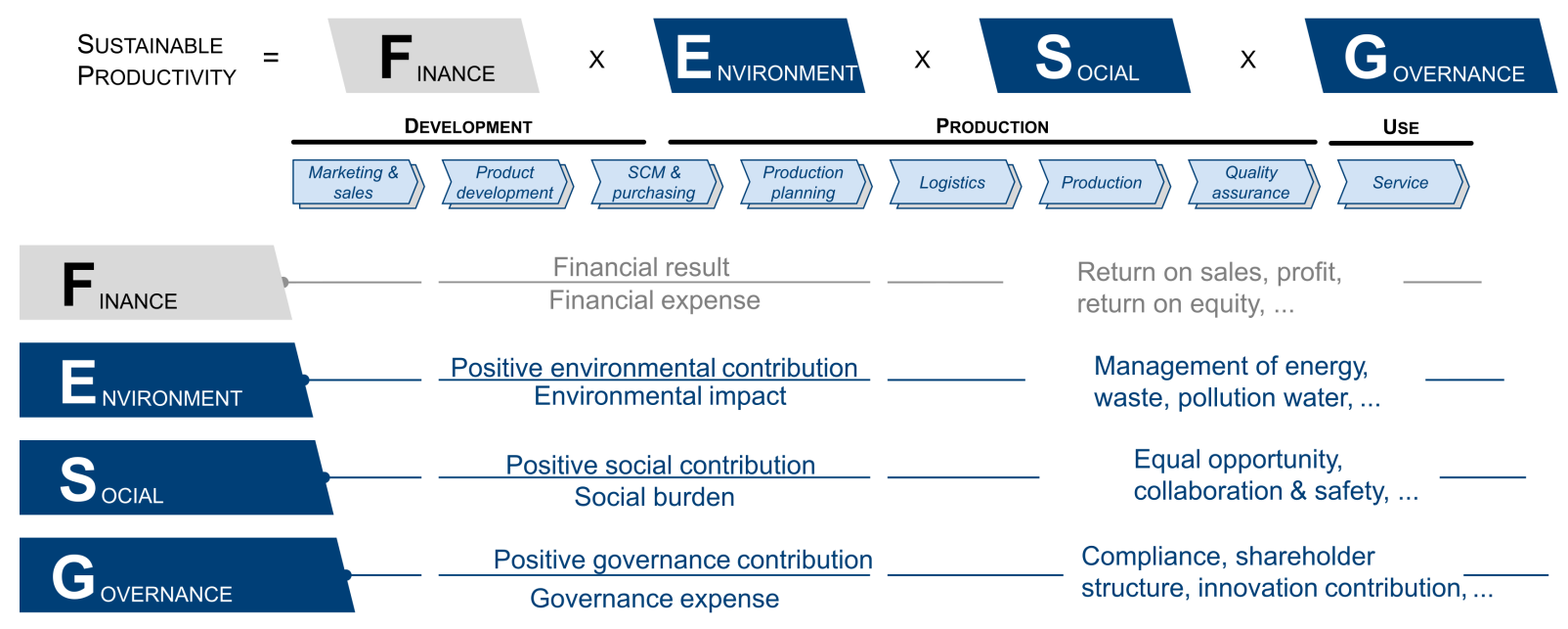

Figure 2. An illustration of holistic assessment of sustainable production [33]. (C) WZL-RWTH Aachen.

\subsection{Factory and Shop Floor}

\subsubsection{General Developments}

The megatrend toward the volatile market environment and individual customer demand poses new challenges, primarily for production systems and management in industrial enterprises, which can significantly influence the profitability and productivity of manufacturing. Within the various presented concepts and frameworks [34-39], automated production systems, including mixed reality assistance systems $[40,41]$, could be rapidly modularized [42] and reconfigured [43-45], enhanced with AI [46,47] and sensors [48,49] and, in combination with cloud and edge computing [50], transformed into distributed control systems, while detailed production environments can be generated and updated in the form of 3D point clouds [51-56]. Based on these infrastructures, DT demonstrates the capability of handling increasingly complex operational problems, such as production 
planning and scheduling [57-60], production monitoring and control [61-66], quality control and management [67-75], as well as logistics [76-78], supply chain management (SCM) [79-81], disassembly and remanufacturing [82-84].

\subsubsection{AI-Integration}

The availability of industrial production data in a networked system landscape acts in this background as a technical enabler to increase the relevance of topics, such as AI and data-driven approaches. This further opens up new potentials for optimizing (novel) manufacturing systems, e.g., line-less mobile assembly systems in Figure 3, which enable agile assembly of large components by leveraging modeling and scheduling systems [85]. The primary objective of utilizing AI at this level is to improve the adaptability of DTs to dynamically changing boundary conditions on the factory and shop floor scale. Typical application subfields with AI-integrated DTs are production planning (Section 2.2.2.1), production control (Section 2.2.2.2), and quality control (Section 2.2.2.3), as shown in Table 1.

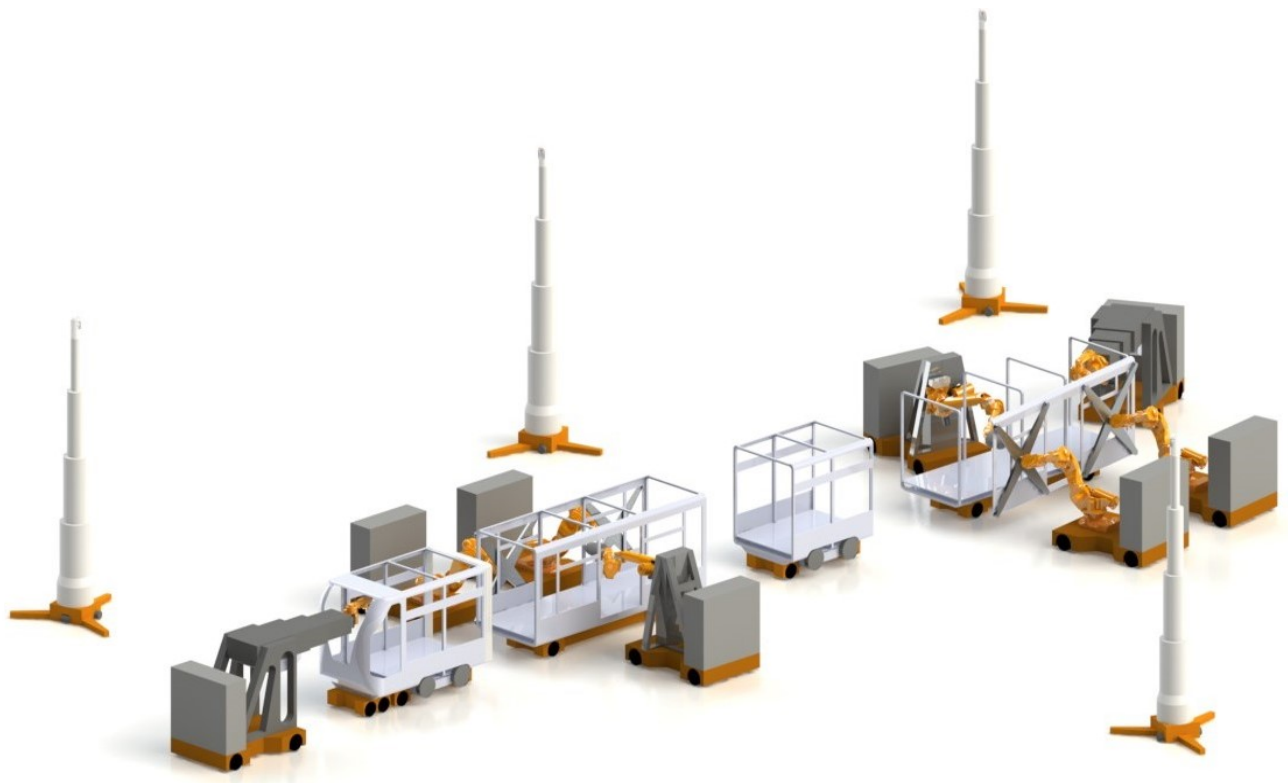

Figure 3. An illustration of DT in manufacturing: line-less mobile assembly system [85]. @ WZLRWTH Aachen.

Table 1. Summary of AI-enabled DTs in smart manufacturing: factory and shop floor level (Section 2.2).

\begin{tabular}{|c|c|c|c|c|}
\hline Subfield & AI-Category & Key Methods & Application-Case & Ref. \\
\hline \multirow{6}{*}{$\begin{array}{l}\text { Production } \\
\text { Planning } \\
\text { (Sec- } \\
\text { tion 2.2.2.1) }\end{array}$} & $\begin{array}{l}\text { Supervised } \\
\text { Learning }\end{array}$ & Decision tree & $\begin{array}{l}\text { Material selection; tool holder selec- } \\
\text { tion; tool wear level prediction }\end{array}$ & [86] \\
\hline & $\begin{array}{l}\text { Reinforcement } \\
\text { Learning }\end{array}$ & DQN & $\begin{array}{l}\text { Dynamic scheduling of flexible manu- } \\
\text { facturing systems }\end{array}$ & [87] \\
\hline & \multirow{4}{*}{$\begin{array}{l}\text { Computational } \\
\text { Intelligence }\end{array}$} & GA, DES & $\begin{array}{l}\text { Optimization of production schedul- } \\
\text { ing }\end{array}$ & [88] \\
\hline & & GA & Optimization of smart assembly lines & [89] \\
\hline & & Supernetwork & $\begin{array}{l}\text { Scheduling optimization of a gear pro- } \\
\text { duction workshop }\end{array}$ & {$[90]$} \\
\hline & & Multi-objective optimization & $\begin{array}{l}\text { Design of automatic flow-shop manu- } \\
\text { facturing system }\end{array}$ & [91] \\
\hline
\end{tabular}


Table 1. Cont.

\begin{tabular}{|c|c|c|c|c|}
\hline Subfield & AI-Category & Key Methods & Application-Case & Ref. \\
\hline \multirow{10}{*}{$\begin{array}{l}\text { Production } \\
\text { Control } \\
\text { (Sec- } \\
\text { tion 2.2.2.2) }\end{array}$} & \multirow{4}{*}{$\begin{array}{l}\text { Supervised } \\
\text { Learning }\end{array}$} & PGM & $\begin{array}{l}\text { Resource allocation for sequential man- } \\
\text { ufacturing operations }\end{array}$ & {$[36]$} \\
\hline & & DNN & $\begin{array}{l}\text { Assembly commissioning process opti- } \\
\text { mization }\end{array}$ & [92] \\
\hline & & AdaBoost, CART, Gradient boosting & $\begin{array}{l}\text { Identification of real-time factors that } \\
\text { influence throughput in a semiconduc- } \\
\text { tor fab }\end{array}$ & [93] \\
\hline & & AdaBoost, XGBoost, decision tree & Optimum yield of the light oil & [94] \\
\hline & \multirow[b]{2}{*}{ Reinforcement } & Deep reinforcement learning & $\begin{array}{l}\text { Geometrical quality improvement in as- } \\
\text { sembly }\end{array}$ & [95] \\
\hline & & Q-Learning & $\begin{array}{l}\text { Box sorting in a material flow control } \\
\text { system }\end{array}$ & [96] \\
\hline & \multirow[t]{4}{*}{ Learning } & DQN & $\begin{array}{l}\text { Optimization of the workflow in a semi- } \\
\text { conductor wafer processing plant }\end{array}$ & [97] \\
\hline & & DQN & Optimization of conveyor systems & [98] \\
\hline & & TRPO & Optimizing order dispatching & [99] \\
\hline & & TRPO & Human behavior forecasting & [100] \\
\hline \multirow{5}{*}{$\begin{array}{l}\text { Quality } \\
\text { Control } \\
\text { (Sec- } \\
\text { tion 2.2.2.3) }\end{array}$} & \multirow{5}{*}{$\begin{array}{l}\text { Supervised } \\
\text { Learning }\end{array}$} & ANN & $\begin{array}{l}\text { Welding quality prediction (deforma- } \\
\text { tion) in an assembly line }\end{array}$ & [101] \\
\hline & & Decision tree, k-NN, SVM & $\begin{array}{l}\text { Anomaly detection of surface devia- } \\
\text { tions of a truck component }\end{array}$ & [102] \\
\hline & & $\mathrm{CNN}$ & Feature recognition of parts & [103] \\
\hline & & ResNet & $\begin{array}{l}\text { Recognizing machining features on } \\
\text { CAD by inputting its views }\end{array}$ & [104] \\
\hline & & $\mathrm{CNN}$, autoencoder, U-Net & $\begin{array}{l}\text { Fringe projection profilometry for 3D } \\
\text { reconstruction }\end{array}$ & [105] \\
\hline Logistics & $\begin{array}{l}\text { Computational } \\
\text { Intelligence }\end{array}$ & Self-learning generic positioning & $\begin{array}{l}\text { Abnormal condition detection and lo- } \\
\text { cation information preservation }\end{array}$ & [106] \\
\hline
\end{tabular}

DQN: Deep Q-Network; GA: Genetic Algorithms; DES: Discrete Event Simulation; PGM: Probabilistic Graphical Model; DNN: Deep Neural Network; AdaBoost: Adaptive Boosting; CART: Classification and Regression Tree; XGBoost: eXtreme Gradient Boosting; TRPO: Trust Region Policy Optimization; ANN: Artificial Neural Network; CNN: Convolutional Neural Network; k-NN: k-Nearest Neighbors algorithm; SVM: Support Vector Machine; ResNet: Residual Neural Network.

\subsubsection{Production Planning}

According to the maturity model of production planning and control (PPC) proposed by Busch et al. [107], toward digitally connected, intelligent and adaptive PPC systems, $\mathrm{AI}$ is envisioned to support production planners in determining plans with improved key performance indicators (KPI), derive optimization measures and autonomously implement the identified measures prospectively to achieve better sequencing and reallocation of resources ( $E$-factor). At the green design and production planning stage, decision tree could be applied in DT to create classic rules used in smart systems, thus facilitating decision making in multidimensional processes and strategic planning [86]. Hu et al. introduced a Petri-net-based dynamic scheduling approach via a deep Q-network (DQN) with graph convolution network (GCN) to solve the dynamic scheduling problems involving shared resources, route flexibility, and stochastic arrivals of raw products [87]. Metaheuristic methods, such as the genetic algorithm (GA) and other optimization methods [88-91] were similarly widely employed to deal with the scheduling problems in production lines. 


\subsubsection{Production Control}

At the production control stage, DNN [92], decision tree [93,94], and tree-based ensemble models, such as AdaBoost [93,94] and XGBoost [94], were implemented in assorted digital production twins to optimize resource allocation and manufacturing performance indicators in a timely manner ( $E$-factor). However, the multi-objective problems at the factory level are usually interpreted as non-deterministic, polynomial-time hard, due to the complexity and dynamics in production environments. To address this challenge, reinforcement learning (RL), such as DQN and deep RL, were employed as a substitute for heuristic optimization and supervised approaches in various investigations, where the major task is normally mathematically formalized as a Markov decision process (MDP), with the objective of autonomously achieving the global optimal economic and logistic KPIs in a factory or logistic simulation environment [96-99] (EG-factor). In order to incorporate humans as a critical element in smart manufacturing, May et al. presented a concept for the situational selection of production control agents by forecasting human behavior modeled through a reinforcement learner [100] (ES-factor).

\subsubsection{Quality Control}

At the quality control stage, classical supervised ML models, such as ANN, decision tree, and SVM, were expected to detect or predict potential deformations and surface deviations in production [101,102]. Deep learning (DL) computer vision models, including residual and convolutional neural networks were deployed to recognize eventual quality issues during the automatic production and machining features of parts $[103,104]$, which could be further utilized to enhance the quality and efficiency of assembly processes [108] (E-factor), or retraced to the production planning stage in order to support decision making on the basis of historical production knowledge [109], as a "smart expert" in a collaborative environment ( $S G$-factor). Following the general concept of integrating ML methods into the digital production twins [110], DTs of production systems in combination with MBSE can be modeled and adapted modularly as a virtual testbed, which in turn could provide a runtime environment for simulation-based optimization [111,112].

\subsubsection{Interim Summary}

Business profitability remains the prerequisite for sustainable operation. DTs at this level elevate the productivity, resilience, and transparency of production processes, which enable end-to-end availability of data along the entire value chain as well as a holistic sustainability assessment on this basis. From a business development perspective, AIenabled DT can additionally be considered a service agent [113], providing innovative smart services via DT network platforms [114] and subscription business models [115], thus contributing sustainably to long-term innovation for manufacturers, and helping them in accomplishing a paradigm shift from the one-time provision of production hardware to the ongoing delivery of manufacturing solutions (SG-factor). The importance of a diversified product and service portfolio is particularly evident in times of global crisis. For small- and medium-sized enterprises (SMEs), innovative services from research institutes and major manufacturing equipment suppliers can facilitate the conduction of the comprehensive balance sheet assessment covering FESG factors in order to achieve a smooth transition to sustainability.

\subsection{Machinery and Equipment \\ 2.3.1. General Developments}

The availability of production machinery and equipment has a direct impact on the efficiency of manufacturing processes and overall equipment effectiveness, and is, therefore, equally significant for sustainable production, especially regarding energy consumption and resource utilization ( $E$-factor). Since their degradation and damage level can be affected by working operations as well as other disturbances in harsh manufacturing environments, such as lubricants, soiling, and temperature, the results from traditional wear and fatigue 
models are connected with considerable uncertainties. DT-driven condition monitoring $(\mathrm{CM})$ and predictive maintenance $(\mathrm{PdM})$ highlight the possibility for the process-parallel monitoring and diagnosis of the health status of the critical components (i.e., tools $[116,117]$, bearings [118], ball screws [119], gears [15,120,121], pumps [122]) and the energy efficiency of the equipment $[123,124]$ in order to handle the conflict between the unplanned maintenance operations and the resulting costs and productivity, particularly in SMEs, due to their limited capacity for the full deployment of a PdM strategy [125]. Additionally, DT-based optimal control [126,127] as well as machine dynamics issues [128,129] from a rotating system [130] to feed drive [131,132] are other important aspects.

\subsubsection{AI-Integration}

Conventional model-based approaches of CM and PdM lie in the evaluation of process indicators, which are either recorded from sensors directly or determined indirectly by them. While the installation of external sensors (e.g., force measurement platforms and rotating dynamometers) increases costs and, more seriously, could negatively affect machine properties and manufacturing stability, DT combined with ML as a promising (soft) sensing technique provides an economically reasonable and sufficiently accurate approach to identifying such indirectly measurable process parameters (EG-factor). Table 2 provides an overview of AI-enabled cases in condition monitoring (Section 2.3.2.1), predictive maintenance (Section 2.3.2.2), and dynamics and control (Section 2.3.2.3).

Table 2. Summary of AI-enabled DTs in smart manufacturing: machinery and equipment level (Section 2.3).

\begin{tabular}{|c|c|c|c|c|}
\hline Subfield & AI-Category & Key Methods & Application-Case & Ref. \\
\hline \multirow{7}{*}{$\begin{array}{l}\text { Condition } \\
\text { Monitoring } \\
\text { (Sec- } \\
\text { tion 2.3.2.1) }\end{array}$} & \multirow{4}{*}{$\begin{array}{l}\text { Supervised } \\
\text { Learning }\end{array}$} & ANN & Prediction of process forces & [133] \\
\hline & & $\mathrm{CNN}$ & Prediction of process forces & [134] \\
\hline & & CNN, SVDD & Defect recognition of steel surfaces & [135] \\
\hline & & $\begin{array}{l}\text { CNN-DLSTM based } \\
\text { transfer learning }\end{array}$ & Fault detection of rolling bearings & [136] \\
\hline & \multirow[b]{2}{*}{$\begin{array}{l}\text { Unsupervised } \\
\text { Learning }\end{array}$} & GAN & Prediction of machining vibration signals & [137] \\
\hline & & $\begin{array}{l}\text { Dictionary learning, } \\
\text { transfer learning }\end{array}$ & $\begin{array}{l}\text { Wave field prediction for damage detection } \\
\text { with ultrasonic guided wave }\end{array}$ & [138] \\
\hline & $\begin{array}{l}\text { Computational } \\
\text { Intelligence }\end{array}$ & Fuzzy inference & Brake $\mathrm{CM}$ of an overhead crane & [139] \\
\hline \multirow{14}{*}{$\begin{array}{l}\text { Predictive } \\
\text { Maintenance } \\
\text { (Sec- } \\
\text { tion 2.3.2.2) }\end{array}$} & \multirow{7}{*}{$\begin{array}{l}\text { Supervised } \\
\text { Learning }\end{array}$} & PGM, MCMC & Prediction of stress-intensity factors and RUL & [140] \\
\hline & & $\mathrm{RCM}$ & Prediction of RUL of a drilling machine & [141] \\
\hline & & RF, particle filter & Prediction of tool wear & [142] \\
\hline & & Deep Stacked GRU & Prediction of tool wear & [143] \\
\hline & & LSTM & Equipment utilization prediction & [144] \\
\hline & & LSTM & Tool condition prognostic model & [145] \\
\hline & & LSTM & Estimation of RUL of the machine components & [146] \\
\hline & \multirow{6}{*}{$\begin{array}{l}\text { Unsupervised } \\
\text { Learning }\end{array}$} & GMM & Tool failure prediction & [147] \\
\hline & & SSAE-PHMM & Prediction of tool wear & [148] \\
\hline & & $\begin{array}{l}\text { SSAE, deep transfer } \\
\text { learning }\end{array}$ & $\begin{array}{l}\text { Fault prognosis in a car body-side production } \\
\text { line }\end{array}$ & [149] \\
\hline & & GAN, VAE & $\begin{array}{l}\text { Generation of a health indicator for PHM of } \\
\text { rotating systems }\end{array}$ & [150] \\
\hline & & CAE & Construction of a health indicator for bearings & [151] \\
\hline & & Distributed k-means & Assessing MAS for collaborative PdM & [152] \\
\hline & $\begin{array}{l}\text { Computational } \\
\text { Intelligence }\end{array}$ & Bayesian network & $\begin{array}{l}\text { Mission planning under uncertainty with re- } \\
\text { spect to fatigue cracking }\end{array}$ & [153] \\
\hline
\end{tabular}


Table 2. Cont.

\begin{tabular}{|c|c|c|c|c|}
\hline Subfield & AI-Category & Key Methods & Application-Case & Ref. \\
\hline \multirow{5}{*}{$\begin{array}{l}\text { Dynamics } \\
\text { \& Control } \\
\text { (Sec- } \\
\text { tion 2.3.2.3) }\end{array}$} & \multirow{2}{*}{$\begin{array}{l}\text { Supervised } \\
\text { Learning }\end{array}$} & RNN & Prediction of dynamic states in metal cutting & {$[154]$} \\
\hline & & ANN & $\begin{array}{l}\text { Prediction of resonances frequencies of a thin } \\
\text { bulk acoustic wave resonator }\end{array}$ & [155] \\
\hline & \multirow{3}{*}{$\begin{array}{l}\text { Computational } \\
\text { Intelligence }\end{array}$} & Gaussian process & $\begin{array}{l}\text { Estimation of single-degree-of-freedom dy- } \\
\text { namic systems }\end{array}$ & [156] \\
\hline & & Gaussian process & Prediction of the dynamic response & [157] \\
\hline & & GWO & $\begin{array}{l}\text { Optimization of motion control system in ma- } \\
\text { chine tools }\end{array}$ & [158] \\
\hline
\end{tabular}

SVDD: Support Vector Data Description; RCM: Random Coefficient Model; RF: Random Forest; MCMC: Markov Chain Monte Carlo; GRU: Gated Recurrent Units; (D)LSTM: (Deep) Long Short Term Memory; GMM: Gaussian Mixture Model; GAN: Generative Adversarial Network; SSAE-PHMM: Stack Sparse AutoEncoder Parallel Hidden Markov Model; VAE: Variational AutoEncoder; CAE: Convolutional AutoEncoder; MAS: Multi-Agent System; RNN: Recurrent Neural Network; GWO: Grey Wolf Optimization.

\subsubsection{Condition Monitoring}

For condition monitoring of machining tools and processes, Königs et al. [133] proposed a hybrid modeling method, whereby an ANN utilized machine internal signals and the cutter-workpiece engagement map generated from a real-time virtual machining simulation as inputs to predict the cutting force as an essential indicator. Su et al. proposed another machining force prediction model based on the cutter frame image data using CNN [134]. Gao et al. [135] introduced a deep lifelong learning method based on CNN and an SVDD-based (support vector data descriptor) detector, which enables recognizing multiple tool defects (crazing, patches, scratches, etc.) with novel classes by learning relevant tool images. CNN-DLSTM based transfer learning [136], generative models [137], and dictionary learning [138] were furthermore employed to assist in abnormal signals detection and fault prognosis ( $E$-factor).

\subsubsection{Predictive Maintenance}

Based on the monitoring status, health indicators, such as remaining useful life (RUL), could be estimated, particularly under non-stationary operation conditions, thus enabling effective predictive maintenance planning (E-factor). Besides statistical [140,141] and hybrid modeling [142] approaches, DL models for time-series forecasting, such as LSTM [144-146], were adopted in numerous studies to estimate wear status and equipment utilization. However, the acquisition of massive, structured and labeled data, especially regarding complex rotating equipment and components, is normally tied up with high costs since the fault-free operation is a frequent case in production. Considering this fact, several attempts with unsupervised and semi-supervised learning models, e.g., GMM (Gaussian mixture model) [147], SSAE (stacked sparse autoencoder) [148,149], and GAN (generative adversarial network) [150], were investigated in order to reduce the reliance on historical failure data in terms of prognostics and health management (PHM). Regarding the cost factor, Palau et al. [152] provided a methodology to assess the optimal multi-agent system (MAS) architecture for collaborative PdM in large fleets of industrial assets by using a distributed k-means clustering algorithm (ES-factor).

\subsubsection{Dynamics and Control}

The manufacturing stability and reliability are furthermore closely related to the dynamic behavior of production machines and process machine interactions (e.g., chatter), namely, dynamics and control, which are due to complex damping effects and structure modification (e.g., tool changing), which are, in practice, difficult to estimate accurately and/or efficiently ( $E$-factor). In this respect, Kabaldin et al. [154] selected RNN to estimate the statistical model of the dynamic state in cutting. ML models, such as ANN [155], and prob- 
abilistic modeling methods, such as the Gaussian process [156,157,159], could likewise be adopted to develop a surrogate model and implemented in a control context $[157,158,160]$. Alternatively, model order reduction techniques can transfer highly detailed and complex simulation models to other domain and life cycle phase, e.g., building efficient finite element model for dynamic structural analysis through reducing the degree of freedom, while maintaining required accuracies and predictability [161-163].

\subsubsection{Interim Summary}

As the backbone of the manufacturing industry, research on machinery and equipment has a protracted history, yet complex and varying working conditions with relatively sparse datasets in practice frequently make it challenging to transfer research findings, commonly in the form of elaborate analytical/empirical models, to real industrial environments. From a data perspective, the networked production landscape provides an additional unique opportunity to use each manufacturing system as a "test bench" in order to continuously enhance the database and the amount of labeled training samples regarding these indirectly measurable and non-measurable indicators. The improved availability of scarce datasets prospectively extends the previous model boundaries and transferability through $\mathrm{ML} / \mathrm{DL}$ in equipment fault diagnosis and system behavior prediction, which remain as central concerns within the scope of sustainable manufacturing ( $E$-factor). High data rates empowered by $5 \mathrm{G}$ technology [164] similarly open up novel prospects for research on AI-driven DTs in the field of PHM, e.g., for sensing high-frequency phenomena in high speed/performance cutting. Figure 4 illustrates the application of digital twin for $\mathrm{CM}$ and PdM in the networked, adaptive production.

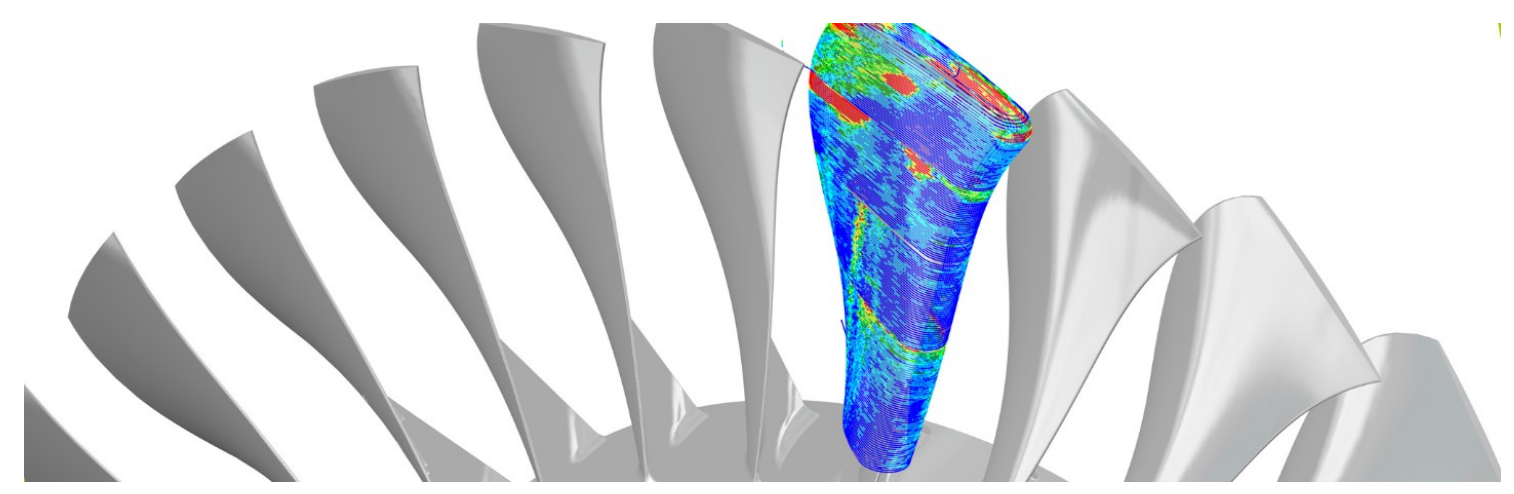

Figure 4. An illustration of DT in manufacturing: CM in the networked, adaptive production [165]. (C) Fraunhofer IPT.

\subsection{Process and Material}

\subsubsection{General Developments}

At this level, we are more concerned about the quality issues and mechanical properties of manufactured parts. The quality of parts is normally determined in quality assurance after the entire machining process by testing quality specifications, such as form and position tolerances, as well as surface roughness. Regarding the optimization of the current quality control loop and the associated costs, the digital process twin represents a core element in modern manufacturing. For instance, the surface quality of parts can be estimated in parallel to the process within a GPU-enabled (graphical processing unit) material removal simulation with a subsequent virtual measurement, which significantly reduces the latency between machining and the detection of defective parts [166,167]. A sufficiently accurate virtual representation of the machining process [26,168-171] also enables cause-and-effect analysis and, therefore, robust process design and control [172-176] as well as the exploitation of potential process productivity [177]. Further cases of production processes with knowledge-based approaches include welding [178,179], injection molding [180,181], linear winding [182], tape laying [183], metal forming [184], laser polishing [185], automated fiber placement [186], sheet molding compound [187], fused filament fabrication [188], and metal additive manufacturing (AM) [189-193]. 


\subsubsection{AI Integration}

While the refining scale of models allows deeper insights into the mechanism of manufacturing processes, their modeling takes correspondingly more time. In addition to leveraging the parallel computing power of GPUs for near real-time process simulation, it is common practice in engineering to compensate online with the results of preprocessed offline simulations. ML and DL methods can thus be trained as surrogate models in order to efficiently update time-consuming numerical simulations at the process and material scale. These ML/DL-equipped lightweight models could be used for faster production ramp-up as well as soft sensory for inline-quality monitoring ( $E G$-factor). They also deliver additional process understanding, thus optimizing the space-time yield and accelerating process development [194]. Table 3 presents a summary of cases of AI-driven digital process twins for major manufacturing techniques involving metal cutting (Section 2.4.2.1), metal AM and laser material processing (Section 2.4.2.2), and composite material processing (Section 2.4.2.3).

Table 3. Summary of AI-enabled DTs in smart manufacturing: process and material level (Section 2.4).

\begin{tabular}{|c|c|c|c|c|}
\hline Subfield & AI-Category & Key Methods & Application-Case & Ref. \\
\hline \multirow{6}{*}{$\begin{array}{l}\text { Metal } \\
\text { Cutting } \\
\text { (Sec- } \\
\text { tion 2.4.2.1) }\end{array}$} & \multirow{4}{*}{$\begin{array}{l}\text { Supervised } \\
\text { Learning }\end{array}$} & $\mathrm{PIO}, \mathrm{SVM}$ & Prediction of surface roughness & [195] \\
\hline & & $\begin{array}{l}\text { Ensemble methods, } \\
\text { ANN }\end{array}$ & $\begin{array}{l}\text { Modeling of the rheological behavior of } \\
\text { drilling fluids }\end{array}$ & [196] \\
\hline & & ANN & $\begin{array}{l}\text { Prediction of stress and fatigue damage (FE } \\
\text { surrogate) of flexible risers }\end{array}$ & [197] \\
\hline & & $\begin{array}{l}\text { DNA-based computing, } \\
\text { Markov chain }\end{array}$ & Prediction of surface roughness & [198] \\
\hline & $\begin{array}{l}\text { Reinforcement } \\
\text { Learning }\end{array}$ & DDPG & $\begin{array}{l}\text { Optimization of decision-making based on } \\
\text { performance and machinability of parts }\end{array}$ & [199] \\
\hline & $\begin{array}{l}\text { Computational } \\
\text { Intelligence }\end{array}$ & PSO & $\begin{array}{l}\text { Inverse determination of material model pa- } \\
\text { rameters from cutting simulation }\end{array}$ & [200] \\
\hline \multirow{5}{*}{$\begin{array}{l}\text { Metal AM } \\
\text { and Laser } \\
\text { Material } \\
\text { Processing } \\
\text { (Sec- } \\
\text { tion 2.4.2.2) }\end{array}$} & \multirow{4}{*}{$\begin{array}{l}\text { Supervised } \\
\text { Learning }\end{array}$} & SVM & $\begin{array}{l}\text { Prediction of the occurrence of defects in metal } \\
\text { AM (LPBF, LMD) }\end{array}$ & [201] \\
\hline & & CNN, LSTM, RNN & Quality assurance in metal AM (LPBF) & [202] \\
\hline & & CART & Prediction of additive manufacturability & [203] \\
\hline & & HMM & $\begin{array}{l}\text { Model adaptivity and quality assessment of } \\
\text { laser material removal processes }\end{array}$ & [204] \\
\hline & $\begin{array}{l}\text { Unsupervised } \\
\text { Learning }\end{array}$ & k-means & $\begin{array}{l}\text { Anomaly detection and process optimization } \\
\text { of 3D laser cutting processes }\end{array}$ & [205] \\
\hline \multirow{5}{*}{$\begin{array}{l}\text { Composite } \\
\text { Material } \\
\text { Processing } \\
\text { (Sec- } \\
\text { tion 2.4.2.3) }\end{array}$} & \multirow{4}{*}{$\begin{array}{l}\text { Supervised } \\
\text { Learning }\end{array}$} & $\mathrm{CNN}$, transfer learning & $\begin{array}{l}\text { Detection of dry points in the production of } \\
\text { carbon fiber reinforced plastics }\end{array}$ & [206] \\
\hline & & AdaBoost, XGBoost, RF & $\begin{array}{l}\text { Prediction of temperature distribution of ther- } \\
\text { moplastic composites }\end{array}$ & [207] \\
\hline & & DNN & $\begin{array}{l}\text { FE surrogate for a composite textile draping } \\
\text { process }\end{array}$ & [208] \\
\hline & & PML & $\begin{array}{l}\text { Prediction of material properties of a compos- } \\
\text { ite material system }\end{array}$ & [209] \\
\hline & $\begin{array}{l}\text { Computational } \\
\text { Intelligence }\end{array}$ & ISRES & $\begin{array}{l}\text { Identification of material parameters of a } \\
\text { prepreg sheet }\end{array}$ & [210] \\
\hline
\end{tabular}


Table 3. Cont.

\begin{tabular}{lllll}
\hline Subfield & AI-Category & Key Methods & Application-Case & Ref. \\
\hline Joining & $\begin{array}{l}\text { Supervised } \\
\text { Learning }\end{array}$ & DNN, GA & Prediction of distortion in welding & [211] \\
\hline Forming & $\begin{array}{l}\text { Supervised } \\
\text { Learning }\end{array}$ & ANN & $\begin{array}{l}\text { Prediction of the ingate velocity during sand } \\
\text { mold filling }\end{array}$ & [212] \\
\hline
\end{tabular}

PIO: Pigeon-Inspired optimization; DDPG: Deep Deterministic Policy Gradient; PSO: Particle Swarm Optimization; HMM: Hidden Markov Model; PML: Probabilistic Machine Learning; ISRES: Improved Stochastic Ranking Evolution Strategy.

\subsubsection{Metal Cutting}

For conventional metal cutting techniques, e.g., milling and drilling, the part quality is primarily determined by sophisticated machine behavior and cutter-workpiece engagement, which can become particularly intricate in multi-axis machining or for parts with thin-walled structures. Zhao et al. constructed a self-learning surface roughness prediction model based on pigeon-inspired optimization and SVM in order to stabilize the part quality with a self-adaptation adjustment method [195]. Approaches combining ANN and semantic modeling for fatigue and quality prediction were discussed in [196-198]. Following the philosophy of DfX (Design for X), Zhou et al. utilized the DDPG (deep deterministic policy gradient) approach to optimize decision making, according to the performance and machinability of parts, which could shorten cycles and save costs in the product development [199] (SG-factor). At the material scale, evolutionary algorithms, such as PSO, were investigated by Hardt et al. to inversely identify the material model parameters in finite element (FE) simulations of orthogonal cutting processes [200].

\subsubsection{Metal AM and Laser Material Processing}

For advanced metal $A M$ and laser material processing techniques, e.g., laser powder bed fusion (LPBF) and laser melting deposition (LMD), research efforts focus on the subtle impacts of thermal effects on materials, such as the microstructure and parts' distortion, during such non-contact processes. As Gaikward et al. in [201] presented the temperature distribution of parts, predicted based on a graph-theoretical computational heat transfer approach and subsequently combined it with an SVM model in order to detect potential quality faults in printing processes. Another attempt of grey box modeling for build quality in dependency of process parameters and in situ sensor signatures was proposed in [202] by Gaikward et al., where the a priori knowledge of physical processes was incorporated into three sequentially connected shallow ANNs and consequently achieved better performance in comparison with purely data-driven methods (CNN, LSTM, RNN, among others). With respect to DfX and knowledge engineering, Ko et al. employed CART to predict additive manufacturability, which was further fed back to a knowledge-query formulation phase in order to continuously construct and broaden an AM knowledge base [203] (EG-factor). In addition, HMM and k-means demonstrated their applications for quality assessing and monitoring in [204,205].

\subsubsection{Composite Material Processing}

For similarly novel but not yet matured composite material processing techniques, e.g., lightweight production of fiber-reinforced polymers, hybrid modeling of non-measurable process variables and process signatures refined therefrom, are anticipated to provide more process understanding and transparency ( $E G$-factor). Stieber et al. proposed a CNN-based transfer learning approach to in situ monitor the polymerization progress of resin transfer molding (RTM) [206]. Hürkamp et al. implemented AdaBoost, XGBoost, and random forest as finite element surrogate models to predict temperature distribution during the fabrication of overmolded thermoplastic composites [207]. Similarly, DNN was applied by Pfrommer et al. as surrogate modeling to optimize the manufacturing process parameters of a composite textile draping process [208]. A probabilistic ML approach with statistical 
inference was developed by Ghanem et al. to efficiently update numeric simulations of a composite material system and reveal multi-scaling relationships of mechanical properties and behaviors [209]. Kanyuck et al. introduced a methodology for identifying sheet material parameters using the ISRES algorithm and implemented a thin-shell simulator for predicting the material behavior, which enabled a defect-free layup of prepreg composite sheets in human-robot collaborative cells [210] (ES-factor).

\subsubsection{Interim Summary}

AI-driven digital process twins are envisioned to learn and interpret implicit correlations between manufacturing processes and material/process/environmental parameters from an aggregation of (heterogeneous) data with the objective of optimizing process development, production ramp-up, and quality assurance cycle. From an engineering implementation perspective, we have noted that despite the significance of algorithms and models, novel sensor technologies [167,213-217] and networked digital process chains [218-222] should not be neglected, as they are essential pillars for constructing DTs and can considerably influence the effectiveness and efficiency of their development and deployment in practice. Figure 5 shows an example of a DT dynamically mapping the manufacturing process of an aerospace part and the data sources involved from the contextualized CADCAM-CNC-CAQ process chain. As yet, these immature manufacturing techniques, such as 3D printing and lightweight production of metals and composites, are still set up in a trial-and-error manner [223]. Their maturation will not only lead to innovative concepts (SG-factor) and resource savings (E-factor) in the design and manufacturing phase, but also provides a pivotal basis for the sustainable operation, maintenance, and reuse of the product downstream, thus reducing energy consumption and carbon emissions across the product lifecycle. The resulting sustainability upgrades are, therefore, all-encompassing.

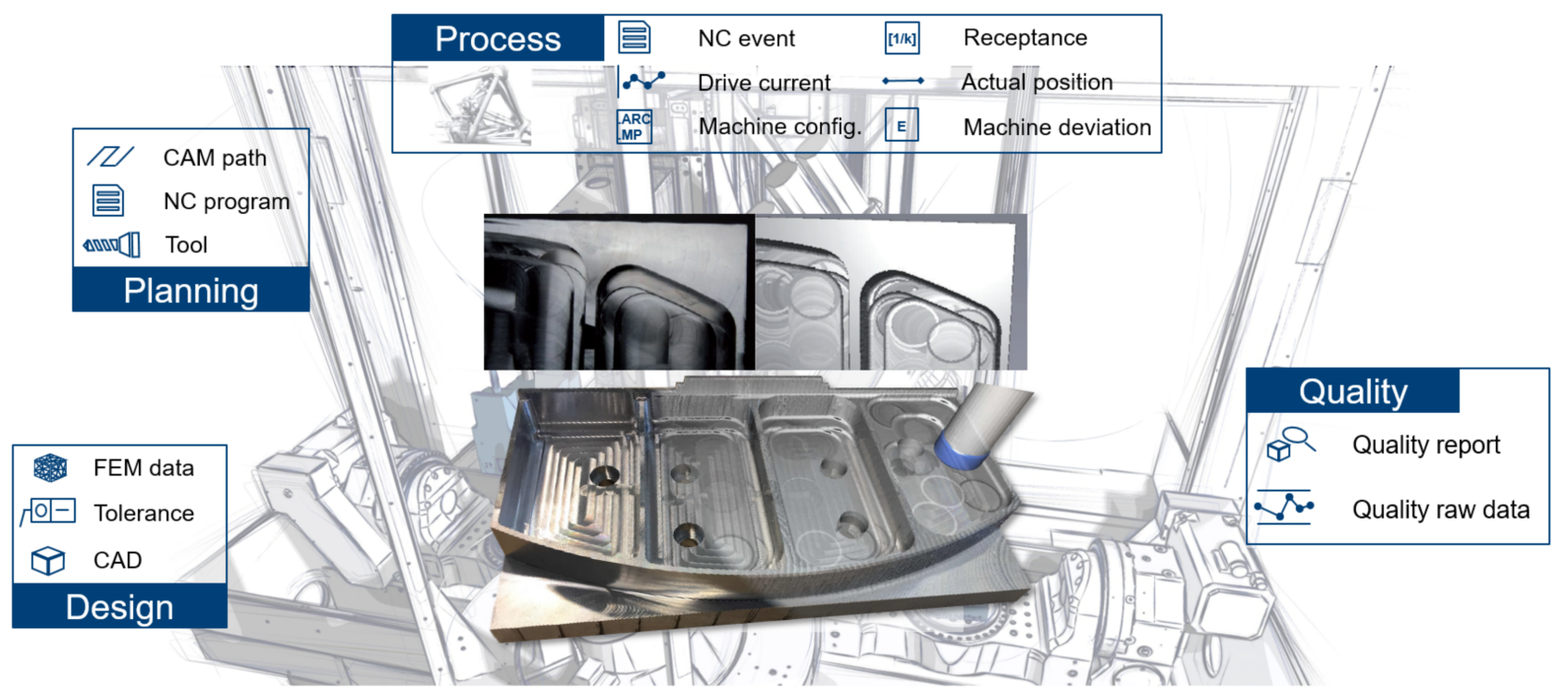

Figure 5. An illustration of DT in manufacturing: workpiece quality monitor [26]. @ WZL-RWTH Aachen.

\subsection{Challenges and Outlook}

Key practical challenges and future work are included as follows.

1. Vertical interoperability in the production context (basis/infrastructure): despite various proposed concepts and cases, a standard framework for developing and deploying multi-scale DTs combining with AI methods has not yet been established. A valid reference framework covering separate manufacturing levels should be defined in the future. For this purpose, interdisciplinary cooperation is indispensable [224].

2. Horizontal interoperability in the production context (basis/data): sufficiently high data quality is a fundamental prerequisite for building AI-driven DTs. In the production 
context, however, the usage of heterogeneous data sources from different software and hardware across the product life cycle is associated with high costs. Through consistently and comprehensively contextualizing and interconnecting of these data silos, the full potential of DTs can be exploited in terms of further optimizing the agility, traceability, resiliency, and transparency of current manufacturing. Interfaces for standard information exchange are, therefore, imperative [225].

3. High-fidelity, lightweight models with uncertainty quantification (core): real manufacturing processes are characterized by numerous, partly stochastic variables with highly complicated cause-effect relationships. In the course of increasing product variants driven by the market, frequently changing technical boundary conditions bring more parameterization efforts and potential uncertainties. Conventional, complex and non-real-time capable models are, therefore, gradually reaching their limits in the industrial environment. In this sense, data-driven approaches with the incorporation of prior knowledge promise to extend the current model boundaries, thereby improving the industrial objectives in terms of productivity, availability, and quality ( $F$-factor).

4. Smart services and business models (application): novel digital platforms contribute to long-range collaboration and innovation, ensembling isolated AI-equipped DT-solutions from diverse levels, and thus offering new opportunities for manufacturers to deliver products and solutions sustainably, e.g., through the X-as-a-Service (XaaS) model. Moreover, the transparency distilled from the entire product value chain serves as an on-demand and real-time capable analytical foundation for the holistic assessment of sustainable resilient manufacturing in order to achieve a balance in the financial, environmental, social, and governance dimensions. The concept of "sustainable productivity" based thereon is depicted in Figure 6 selected from the white paper by Boos [33]. Therein, the vision of "Internet of Production" provides the infrastructure for harnessing data along the product lifecycle [226], while the transparency generated from the (AI-powered) DTs enables product design, manufacturing, and usage exclusively, according to actual demand-, quantity-, and user-oriented requirements [33].

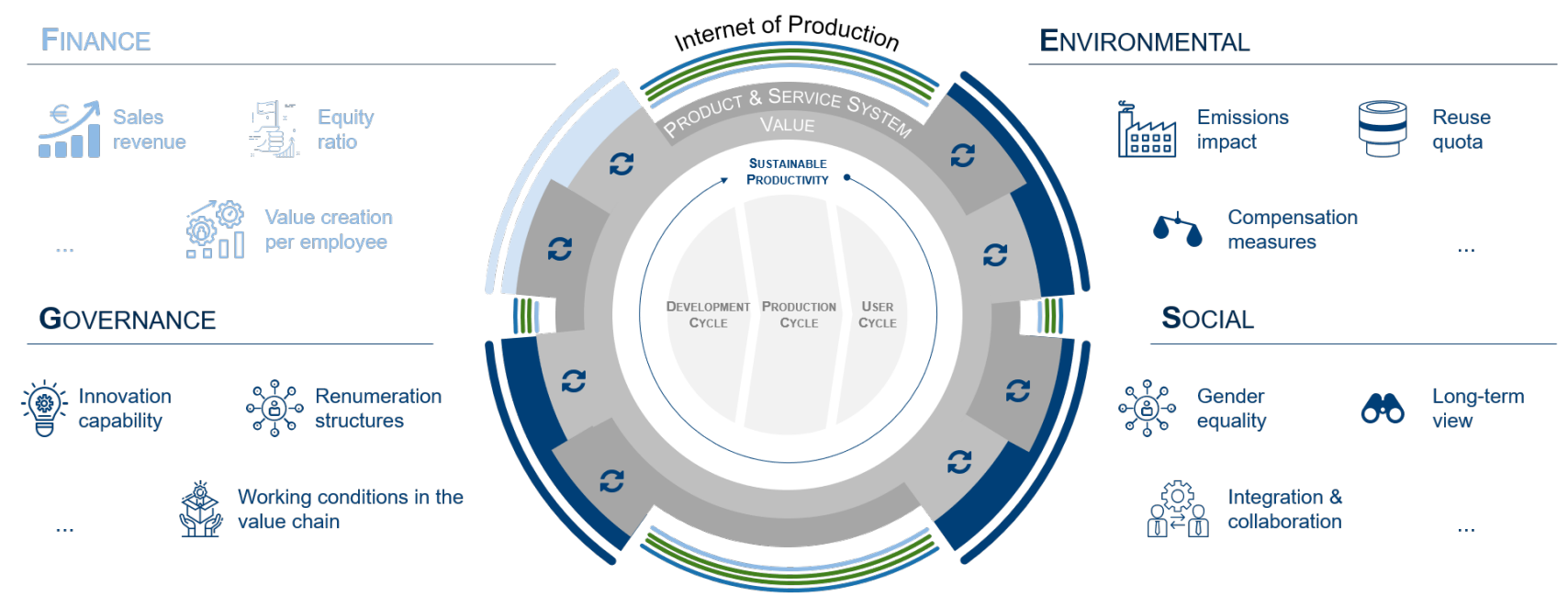

Figure 6. An illustration of sustainable resilient manufacturing [33]. C WZL-RWTH Aachen.

\section{Advanced Robotics}

\subsection{Overview}

Along with the widespread deployment of robotic systems in industry and daily life [227], having a digital twin of robots becomes more and more critical in practical scenarios, such as multi-robot coordination/collaboration as well as those that require safe humanrobot interaction (HRI) and/or complex human-robot collaboration (HRC) [228-231], which place human safety as a high priority, thus helping to create a sustainable working environment ( $S G$-factor). Many have used traditional simulation/cloud framework to 
attempt robot DT implementations, such as the ones shown in Figures 7 and 8. Other examples could be found in kinematics [232], communication [233,234], control [235-237], planning [238], and industrial robot energy modeling [239], in use cases like welding [240], cleaning [241], pick-and-place [242], assembly [243-246], manufacturing [247], warehouse [248,249], maintenance [250], and construction [251]. Some well-known robotics simulation tools are Gazebo [252], MuJoCo [253], and CoppeliaSim (aka V-REP) [254]. Recently, new concepts and cases utilizing artificial intelligence towards semi- and fully autonomous robotic systems have been reported, e.g., transfer learning [255] and imitation learning (also known as apprenticeship learning or learning from demonstration) [256,257]. While traditional DTs have been developed for systems that we have a solid grasp of (in other words, modelbased), data-driven and AI-equipped DTs help with complex robotic systems for which building high-fidelity dynamics models is not feasible (model-free). The latter has been applied in more and more cases, even for biomimetic robotic system development (e.g., robotic fish [258]). Table 4 summarizes AI-equipped DTs and categorizes them based on learning algorithms used and subfields, such as control (detailed in Section 3.2), planning (detailed in Section 3.3), and HRI/HRC (detailed in Section 3.4).
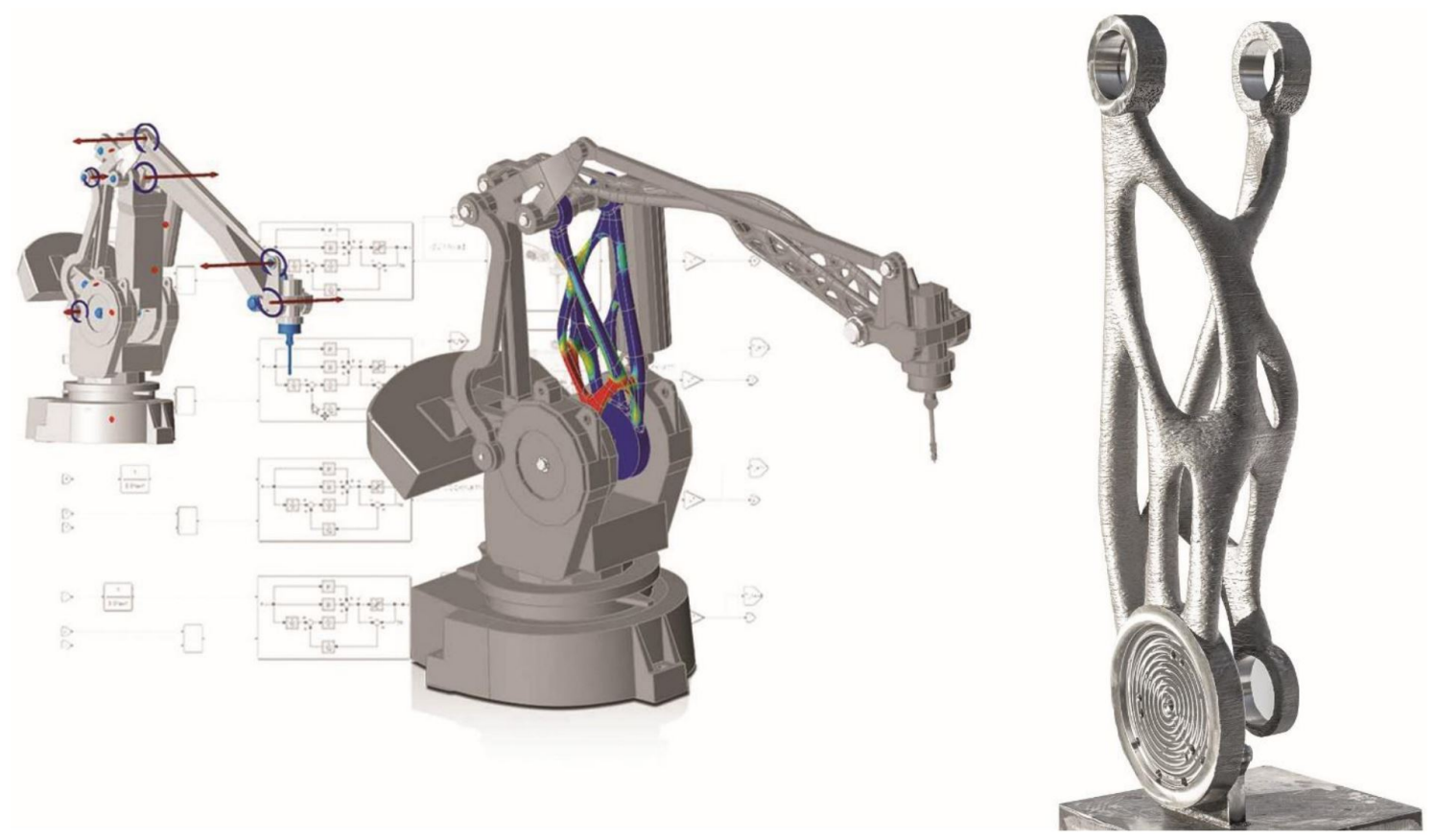

Figure 7. An illustration of DT in robotics: in a joint project MX3D, ABB, and Altair demonstrated how a 3D-printed robot can be improved by using a digital twin process to achieve more precise positioning [259]. (CAltair.

Table 4. Summary of AI-enabled DTs in advanced robotics.

\begin{tabular}{lllll}
\hline Subfield & AI Category & Key Methods & Application-Case & Ref. \\
\hline & $\begin{array}{l}\text { Supervised and Unsuper- } \\
\text { vised Learning }\end{array}$ & SVM, PCA & Object recognition of a smart gripper & [260] \\
\cline { 2 - 5 } & Reinforcement learning & Trial-and-error search & Weightlifting robot control & [261] \\
\cline { 2 - 5 } $\begin{array}{l}\text { Control } \\
\text { (Section 3.2) }\end{array}$ & Supervised Learning & GD & $\begin{array}{l}\text { Understanding the added value of integrated } \\
\text { models for through-life engineering services }\end{array} \quad$ [262] \\
\cline { 2 - 5 } & $\begin{array}{l}\text { Computational } \\
\text { Intelligence }\end{array}$ & Vision-based Markovian chain & $\begin{array}{l}\text { Automate fan-blade reconditioning for } \\
\text { aerospace maintenance, repair and overhaul [263] }\end{array}$ \\
\cline { 2 - 5 } & QP & $\begin{array}{l}\text { Supporting rescuers on disaster-response mis- } \\
\text { sions }\end{array}$ \\
\hline [264]
\end{tabular}


Table 4. Cont.

\begin{tabular}{|c|c|c|c|c|}
\hline Subfield & AI Category & Key Methods & Application-Case & Ref. \\
\hline \multirow{5}{*}{$\begin{array}{l}\text { Planning } \\
\text { (Section 3.3) }\end{array}$} & \multirow{4}{*}{$\begin{array}{l}\text { Reinforcement } \\
\text { Learning }\end{array}$} & Proximal policy optimization & $\begin{array}{l}\text { Pick-and-place tasks for an industrial robotic } \\
\text { arm }\end{array}$ & {$[265]$} \\
\hline & & DDPG & $\begin{array}{l}\text { Control and trajectory planning of a planar 3- } \\
\text { DOF manipulator and 3D arms of a humanoid } \\
\text { robot }\end{array}$ & {$[266]$} \\
\hline & & DQN & Automate smart manufacturing systems & [267] \\
\hline & & Proposed LSTM-MACG & $\begin{array}{l}\text { Collision avoidance for a number of UAVs in } \\
\text { a confined airspace }\end{array}$ & {$[268]$} \\
\hline & Computational Intelligence & Ant colony optimization & Path planning of industrial robots & [269] \\
\hline \multirow{6}{*}{$\begin{array}{l}\text { HRI/HRC } \\
\text { (Section 3.4) }\end{array}$} & \multirow{4}{*}{$\begin{array}{l}\text { Supervised } \\
\text { Learning }\end{array}$} & CNN & Standing-posture recognition in HRC & {$[270]$} \\
\hline & & $\mathrm{DL}$ & Mechatronics system & {$[271]$} \\
\hline & & ANN & Enabling industrial robots to bypass obstacles & {$[272]$} \\
\hline & & LSTM & Visual question answering for HMC system & {$[273]$} \\
\hline & $\begin{array}{l}\text { Supervised and Unsuper- } \\
\text { vised Learning }\end{array}$ & FFT-PCA-SVM & $\begin{array}{l}\text { HRI welding and welder behavior analysis } \\
\text { (identifying the professional level) }\end{array}$ & {$[274]$} \\
\hline & Reinforcement Learning & DDPG & $\begin{array}{l}\text { COVID-19, improve efficiency in assembling } \\
\text { medical equipment }\end{array}$ & {$[275]$} \\
\hline \multirow[b]{2}{*}{$\begin{array}{l}\text { Predictive } \\
\text { Maintenance }\end{array}$} & \multirow[b]{2}{*}{$\begin{array}{l}\text { Supervised } \\
\text { Learning }\end{array}$} & \multirow[b]{2}{*}{ DNN } & System health monitoring & {$[276]$} \\
\hline & & & $\begin{array}{l}\text { Maximizing the overall plant availability of } \\
\text { modern manufacturing systems }\end{array}$ & {$[277]$} \\
\hline $\begin{array}{l}\text { Workspace } \\
\text { Modeling }\end{array}$ & Supervised Learning & Monte Carlo method & Simulating the workspace of the mechanisms & {$[278]$} \\
\hline Others & Supervised Learning & $\mathrm{RF}$ & $\begin{array}{l}\text { Estimation of lawn grass lengths for robotic } \\
\text { lawn mower }\end{array}$ & {$[279]$} \\
\hline
\end{tabular}

PCA: Principal Component Analysis; GD: Gradient Descent; QP: Quadratic Programming; MACG: MultiAgent Computational Guidance; FFT: Fast Fourier Transform; UAV: Unmanned Aerial Vehicle.

\subsection{Control}

A key part of modern robotic control is feedback, which expects accurate information collected from physical sensors installed on robots and in the external environment and to provide commands for the next loop of execution. Sometimes, real time is required to enable safer controllers on these robotic systems. Many efforts utilizing AI + DT have been attempted in this subfield. Compared with traditional DTs, those equipped with AI and driven by data have advantages of gaining better generalizability and higher adaptability in a varying environment, and accomplishing nontrivial sensing/manipulation tasks. At the sensing stage, Jin et al. reported a smart soft-robotic gripper system based on triboelectric nanogenerator sensors to capture the continuous motion and tactile information for soft gripper control, where PCA and SVM were used to realize real-time prediction [260]. Data- or AI-driven approaches can also be found in other touch/haptic/force sensing for obtaining better system understanding and task performance [280-282]. One level higher, at the controller stage, Verner et al. implemented online reinforcement learning via a fabricated digital twin, to enable a humanoid robot to lift a weight of unknown mass through autonomous trial-and-error search [261]. Similarly, in [283], Grinshpun et al. reported the development and deployment of control algorithms for soft robots, with particular reference to industrial peg-in-hole insertion tasks. Vrabič et al. used DT and gradient descent to optimize controller parameters of a mobile robot [262]. More data/AI-driven examples in robot control include [284,285]. At the application level, one example is that Oyekan et al. utilized vision-based Markovian chain to automate fan-blade reconditioning for aerospace maintenance, repair and overhaul with a 6DOF robotic arm [263] (E-factor). Another example is that Klamt et al. built a DT for the famous CENTAURO robotic system to support rescuers on disaster response missions [264] (S-factor). 


\subsection{Planning}

Once the low-level robotic control is in good shape, the high-level robotic planning, as another critical part of realizing autonomous robotic systems, comes into play. Unlike the low-level control subfield, which emphasizes the system response and robustness, highlevel planning focuses more on strategically finding a close-to-optimal solution among all feasible options, under specific constraints. Compared with traditional search-based motion planning algorithms, reinforcement learning has demonstrated huge potentials in bringing intelligence to complex systems planning, e.g., a humanoid robot with high degrees of freedom (DOFs) [286]. However, it is usually difficult to train reinforcement learning because obtaining the data from the real physical system is both finance- and time-consuming. The curse of dimensionality may also disable the system from learning something useful [287]. As a robotic system's digital twin grows up and provides reliable data, the combination "DT + RL" seems to be a promising approach (SG-factor): in [265], Matulis et al. integrated digital twin and reinforcement learning for a 6DOF robotic manipulator to plan pick-and-place motions; in [266], Liu et al. proposed a multitaskingoriented robot arm motion planning scheme based on deep reinforcement learning and twin synchro-control; in [267], Xia et al. proposed a DT to train deep reinforcement learning agent for automating smart manufacturing systems; and in [268], Zhao et al. demonstrated collision avoidance for a number of UAVs in a confined airspace, using LSTM-MACG. While RL has become popular in recent years, it is not the only AI strategy that is integrated with DTs. For example, Bansal et al. developed an ant colony optimization algorithm for industrial robot programming in a digital twin [269].



Figure 8. An illustration of DT in robotics: Altair digital twin platform [288]. (CAltair.

\subsection{HRI and HRC}

Under the context of Industry 4.0, one of the very important benefits that DT could bring to robot-involved scenarios is safer human-robot interaction and human-robot collaboration [289,290] (SG-factor). HRI and HRC scenarios are, intuitively, more complex and challenging than robot-only applications, due to not only the uncertainties in the environment and sensors, but also the randomness and diversity of human behavior. One of the advantages of AI-equipped DTs over conventional ones is the ability to better respond to these (sometimes implicit, such as [291]) variables that are nontrivial to exhaustively model and analyze. For example, in [292], Wang et al. proposed a real-time processlevel digital twin for collaborative human-robot construction work. The proposed DT 
utilized immersive virtual reality (VR) and combined the as-designed BIM model and the evolving as-built workspace geometry obtained from on-site sensors, to provide the capability for both planning and improvising. Similarly, in [270], Li et al. proposed DLbased human standing-posture recognition in HRC. Other supervised learning applications, such as visual question answering for the HMC system, are included in Table 4 [271-273]. A supervised/unsupervised learning example is [274], where Wang et al. used FFTPCA-SVM-based DT for human-robot interactive welding and welder behavior analysis. In [275], Lv et al. proposed a reinforcement learning-based DT for improving medical equipment assembly efficiency during COVID-19.

\subsection{Robot Maintenance and Other Applications}

Robotic systems, like other machines with a physical entity, have downtime and need maintenance as well ( $E$-factor). Without explicitly mentioning the concept of DT, Khalastchi et al. and Vallachira et al. reported applications of using data-driven methods in robot anomaly/failure detection in [293] and [294], respectively. In [276], Anton et al. used deep learning equipped DT for global system health monitoring as well as predictive, customized maintenance. Similarly, in [277], Aivaliotis et al. integrated degradation curves in the predictive maintenance of industrial robots. Some other applications, such as using the Monte Carlo learning method in calculating the workspace of a serial robot manipulator [278] and random forest based estimation of lawn grass lengths for robotic lawn mower [279], can be found in Table 4.

\subsection{Challenges and Outlook}

There are several key challenges in developing and implementing digital twins in the field of robotics [295,296]. First, the multibody physical simulation is intrinsically difficult, due to the complex interaction properties at the interfaces of robot-robot, robot-human, and robot-environment. In addition, since robot movement can often be extremely fast (e.g., in an assembly line), real-time feedback from sensors is critical to the digital twin's effectiveness in making short-term decisions. Many researchers in academia choose to use simulators, such as Gazebo (e.g., [297,298]), as the simulation environment for developing robots, but even after years of evolution, those robotic simulators still have many unsolved limitations and may require high-performance computing (HPC) platforms. Second, inputs and disturbances from the human user add another layer of uncertainty and unpredictability to the whole collaborative system/workspace, and thus, compromise HRI/HRC safety. While standard-compliant (e.g., ISO 13482) safety measures must be facilitated on both physical and digital sides, having virtual reality or augmented reality (AR) technologies involved is another thread to make the human-robot interaction intuitive [299]. Rückert et al. also suggested the consolidation of product life cycle information within human-robot collaborative assembly tasks [300].

\section{Discussion}

DTs have shown remarkable potentials to contribute to industrial economic growth or $F$-factor (i.e., the productivity, availability, and quality of manufacturing) while continuously upgrading sustainable aspects, such as the $E$-factor (e.g., reduced carbon emission and resource consumption through $\mathrm{CM}, \mathrm{PdM}, 3 \mathrm{D}$ printing and lightweight production of metals and polymers) and $S G$-factor (e.g., enhanced working conditions, collaboration and innovation through HRI/HRC, XaaS model, and intelligent/soft sensing of novel production indicators) as summarized in Table 5. In this range of cross-domain engineering cases, AI techniques arm digital twins with tools to create models based on observed behavior and historical data, which improves the efficiency of data analysis and increases prediction accuracy by integrating data from a collection of disparate and incompatible sources. 
Table 5. Summary of AI-enabled DTs in sustainable development and FESG factors.

\begin{tabular}{lll}
\hline F-Factor & E-Factor & SG-Factor \\
\hline $\begin{array}{l}\text { Productivity } \\
\text { (Section 2.2) }\end{array}$ & $\begin{array}{l}\text { Production Planning (Section 2.2.2.1) } \\
\text { Production Control (Section 2.2.2.2) } \\
\text { Quality Control (Section 2.2.2.3) }\end{array}$ & $\begin{array}{l}\text { Intelligent Sensing of Novel Indicators } \\
\text { (Sections 2.2.2, 2.3.2 and 2.4.2) }\end{array}$ \\
$\begin{array}{l}\text { Availability } \\
\text { (Section 2.3) }\end{array}$ & $\begin{array}{l}\text { Condition Monitoring (Section 2.3.2.1) } \\
\text { Predictive Maintenance (Section 2.3.2.2) }\end{array}$ & $\begin{array}{l}\text { Innovative Robot Planning and Control } \\
\text { (Sections 3.2 and 3.3) }\end{array}$ \\
& $\begin{array}{l}\text { Dynamics and Control (Section 2.3.2.3) } \\
\text { Robot Maintenance (Section 3.5) }\end{array}$ & HRI/HRC (Section 3.4) \\
Quality & Metal Cutting (Section 2.4.2.1) & DfX (Sections 2.4.2.1 and 2.4.2.2) \\
& $\begin{array}{l}\text { Metal Additive Manufacturing (Section 2.4.2.2) } \\
\text { Composite Material Processing (Section 2.4.2.3) }\end{array}$ & XaaS and Business Model (Section 2.2.3) \\
\hline
\end{tabular}

The AI techniques involved in digital twins can be roughly categorized into four classes: supervised learning, unsupervised learning, reinforcement learning and other intelligent computational methods. Supervised learning algorithms refer to machine learning methods in which models are trained using labels. Typical supervised learning methods used in digital twin include supper vector machine (SVM) [195,201], decision trees [86,93,94], k-nearest neighbors [102], convolutional neural networks (CNN) [103,135,202,206,270] and recurrent neural networks (RNN) [202]. In practice, data labeling can be an expensive task. Most supervised learning algorithms require a large amount of labeled data at the training stage to obtain a model with high prediction accuracy. In general, the more complex the architecture is, the more data are needed to produce viable results. The results of supervised learning algorithms also depend on the selection of feature vectors and the accuracy of labeling.

In unsupervised learning methods, there is no labeling of data required, and the model is expected to infer patterns from the unlabeled input data. Clustering algorithms, such as principle component analysis (PCA) [260,274] and k-means methods [205] and generative models using generative adversarial network (GAN) [137,150] and variational autoencoders (VAE) [150] all use unlabeled data at the training stage, thus falling into the category of unsupervised learning. One of the challenges in applying unsupervised learning methods is that the number of clusters is normally not known a priori. For clustering algorithms, the clusters are determined by the metric used to measure similarity-Euclidean, cosine, Gaussian distance-of which the criteria are not clear for a given task. Reinforcement learning algorithms are concerned with how intelligent agents ought to take actions in an environment in order to maximize the notion of cumulative reward. Researchers have applied reinforcement learning algorithms, including Q-learning [96], deep reinforcement learning $[95,97,267]$ and deep deterministic policy gradient $[199,266,275]$ to optimize the decision-making process of box sorting, conveyor systems and other DT scenarios. The performance of a reinforcement learning system generally heavily depends on the correctness of data logging and the choice of reward structures. Logging to incorrect references might corrupt the information and lead the whole system to break down during training.

From the above, the fidelity of AI-driven DTs depends largely on the model granularity, the selection of which (core level) is, in turn, related to the environment complexity (application level) and dataset quality (basis level). Based on the review of over 300 manuscripts, we sketched a route for AI-integration in multiscale/fidelity DTs in the real-world case of multiscale/fidelity data sources, as outlined in Figure 9. This multiscale nature is reflected in both spatial and temporal terms. Vertically, the demand for real-time capability in digital twins alters with different levels of the automation pyramid. While the higher-scale planning and management typically require a longer response time to deal with changing 
production environments, time-sensitive sensing and manipulation rely on the in-depth insight of physical processes gained through refining scale modeling. Horizontally, datasets of varying difficulty and fidelity are constructed from heterogeneous sources over the product lifecycle. In the development phase, simulation tools and laboratory experiments separately provide comparatively large amounts of data with a moderate degree of fidelity and limited high-accuracy data under controlled conditions. As products are manufactured and utilized, obtaining reliable labeled data, such as quality indicators and RUL, becomes increasingly scarce and expensive. On this basis, AI methods can be developed and deployed in pipelines. In general, supervised learning remains the most stable and extensively used approach in digital twins. Reinforcement learning is often advantageous in scenarios with complex environments and long response cycles, unsupervised and semi-supervised learning are quite proactive in state detection and lifetime prediction, and traditional intelligence methods are still commonly used and can be flexibly combined with other learning methods.



Figure 9. An illustration of AI-integration in multiscale/fidelity DTs along the product lifecycle.

\section{Summary}

Traditional profit-maximizing industrial technologies have transformed human society while causing significant-and mostly irreversible - negative impacts on the environment and climate. Sustainable development strategies are gaining attention, but still have a long way to go, as all aspects within the FESG dimensions have to be balanced in real implementation. According to a report from the WBA Tooling Academy Aachen [301], classic evaluation for manufacturing companies with a focus on value added and equity ratio could show a significantly worse outcome in the extended analysis that incorporates ESG criteria in the balance sheet. For sustainable thinking and practices, which have been increasingly deliberated and advocated worldwide, digitalization and AI are powerful enablers. Through consistently linking, processing, and analyzing all available data across the entire value chain, and connecting them to a digital twin or shadow, a holistic assessment of sustainability, namely, the consideration of ESG factors alongside profitability ( $F$-factor), can be achieved so that companies can develop and operate sustainably. For Industry 4.0, which is facing new challenges from climate-neutral products and production, AI-driven DTs are expected to provide the additional manufacturing transparency and 
understanding that enable a demand-oriented and real-time capable analytical foundation, considering FESG factors along the product lifecycle. The main contributions of this study are concluded as follows.

1. The general development and application cases with common AI methods in AI-driven DTs of Industry 4.0 are concluded.

2. The advantages of AI-driven DTs in sustainable development are elaborated regarding the FESG factors, which enable a quantitative assessment of sustainability.

3. Challenges and development prospects of AI-driven DTs in smart manufacturing and advanced robotics are discussed with a respective focus on different levels.

4. A route for AI integration in multiscale/fidelity DTs with multiscale/fidelity data sources along the product lifecycle is outlined.

In the past, typical production issues, such as predicting the behavior of machine tools as single systems, were already well approximated by complex analytical and empirical models; their application in industry environments, however, has often been handicapped, due to both the lack of real-time capabilities and transferability in varying frameworks. AI promises in this circumstance to extend the model boundaries of traditional modelbased approaches, particularly within changing boundary conditions. As regards the relatively sparse and expensive datasets in engineering, incorporating prior knowledge can reduce the dependence of pure data-driven approaches on the amount of historical data and improve the predictivity and transferability of models. Moreover, statistically-based uncertainty quantification similarly plays an essential role in building AI-driven DTs, as it allows to assess the reliability of the modeled results and, thus, influences their acceptance and the decision-making based thereon in real, high-risk engineering.

Meanwhile, we have noted that the development and deployment of AI-enabled algorithms and models, the core of the DT, are still constrained by the current infrastructure and that constructing the latter requires interdisciplinary collaboration and integration of domain-specific expertise (basis level). New breakthroughs in novel sensors and benefits from 5G communications and OPC UA TSN are expected in the near future. In terms of the application level, while smart service and new business models facilitate the paradigm shift for manufacturers, a prerequisite is the willingness to share data and knowledge with partners to a healthy extent. Standardized concepts for data ownership and data security must constitute the basis for this. A further survey on the AI-driven DT technologies in the application fields of renewable energy, smart city and mobility, and healthcare will be covered in future work. By reorganizing and aggregating several highly relevant topics both horizontally and vertically, we believe that a synergistic effect will emerge that can allow the work in this study to contribute to more AI-driven, DT-related research and help various branches build new developments in their respective sustainable and smart areas.

Author Contributions: Conceptualization, Z.H. and Y.S.; writing, Z.H., Y.S. and J.L.; supervision: M.F. and C.B. All authors have read and agreed to the published version of the manuscript.

Funding: This research was partially funded by the Deutsche Forschungsgemeinschaft (DFG, German Research Foundation) through the Cluster of Excellence "Internet of Production"-390621612.

Institutional Review Board Statement: Not applicable.

Informed Consent Statement: Not applicable.

Data Availability Statement: Not applicable.

Acknowledgments: The authors would like to thank the German Research Foundation DFG for the support within the Cluster of Excellence "Internet of Production"-390621612. The authors would also like to thank Altair Engineering, Inc., Fraunhofer IPT, as well as the Chair of Production Metrology and Quality Management, and Production Engineering of the Laboratory for Machine Tools and Production Engineering (WZL) for their permission to reuse the images.

Conflicts of Interest: The authors declare no conflict of interest. 


\section{Abbreviations}

The following abbreviations are used in this manuscript:

\begin{tabular}{|c|c|}
\hline AdaBoost & Adaptive Boosting \\
\hline AI & Artificial Intelligence \\
\hline $\mathrm{AM}$ & Additive Manufacturing \\
\hline ANN & Artificial Neural Network \\
\hline AR & Augmented Reality \\
\hline CAD & Computer-Aided Design \\
\hline CAE & Convolutional AutoEncoder \\
\hline CAM & Computer-Aided Manufacturing \\
\hline CAQ & Computer-Aided Quality Assurance \\
\hline CART & Classification and Regression Tree \\
\hline $\mathrm{CM}$ & Condition Monitoring \\
\hline $\mathrm{CNC}$ & Computer Numeric Control \\
\hline $\mathrm{CNN}$ & Convolutional Neural Network \\
\hline CRM & Customer Relationship Management \\
\hline DBN & Dynamic Bayesian Network \\
\hline DDPG & Deep Deterministic Policy Gradient \\
\hline DES & Discrete Event Simulation \\
\hline DfX & Design for $X$ \\
\hline DL & Deep Learning \\
\hline DNN & Deep Neural Network \\
\hline DOF & Degrees of Freedom \\
\hline DQN & Deep Q-Network \\
\hline DT & Digital Twin \\
\hline ERP & Enterprise Resource Planning \\
\hline FE & Finite Element \\
\hline FFT & Fast Fourier Transform \\
\hline GA & Genetic Algorithm \\
\hline GAN & Generative Adversarial Network \\
\hline GCN & Graph Convolution Network \\
\hline GD & Gradient Descent \\
\hline GMM & Gaussian Mixture Model \\
\hline GP & Gaussian Process \\
\hline GPT & General-Purpose Technology \\
\hline GPU & Graphical Processing Unit \\
\hline GRU & Gated Recurrent Units \\
\hline GWO & Grey Wolf Optimization \\
\hline HMC & Human-Machine Collaboration \\
\hline HMM & Hidden Markov Model \\
\hline $\mathrm{HPC}$ & High-Performance Computing \\
\hline HRC & Human-Robot Collaboration \\
\hline HRI & Human-Robot Interaction \\
\hline IoT & Internet of Things \\
\hline ISRES & Improved Stochastic Ranking Evolution Strategy \\
\hline $\mathrm{k}-\mathrm{NN}$ & k-Nearest Neighbors algorithm \\
\hline KPI & Key Performance Indicators \\
\hline LMD & Laser Melting Deposition \\
\hline LPBF & Laser Powder Bed Fusion \\
\hline LSTM & Long Short-Term Memory \\
\hline MAS & Multi-Agent System \\
\hline MBSE & Model-Based System Engineering \\
\hline MCMC & Markov Chain Monte Carlo \\
\hline
\end{tabular}




\begin{tabular}{|c|c|}
\hline MDP & Markov Decision Process \\
\hline MES & Manufacturing Execution System \\
\hline ML & Machine Learning \\
\hline NASA & National Aeronautics and Space Administration \\
\hline NIST & National Institute of Standards and Technology \\
\hline $\mathrm{NN}$ & Neural Network \\
\hline PCA & Principal Component Analysis \\
\hline PDA & Production Data Acquisition \\
\hline PdM & Predictive Maintenance \\
\hline PGM & Probabilistic Graphical Model \\
\hline PHM & Prognostics and systems Health Management \\
\hline PIO & Pigeon-Inspired Optimization \\
\hline PLM & Product Lifecycle Management \\
\hline PML & Probabilistic Machine Learning \\
\hline PPC & Production Planning and Control \\
\hline PSO & Particle Swarm Optimization \\
\hline QP & Quadratic Programming \\
\hline $\mathrm{RCM}$ & Random Coefficient Model \\
\hline ResNet & Residual Neural Network \\
\hline RF & Random Forest \\
\hline RL & Reinforcement Learning \\
\hline RNN & Recurrent Neural Network \\
\hline RTM & Resin Transfer Molding \\
\hline RUL & Remaining Useful Life \\
\hline SCM & Supply Chain Management \\
\hline SME & Small and Medium-sized Enterprise \\
\hline SSAE-PHMM & Stack Sparse AutoEncoder Parallel Hidden Markov Model \\
\hline SVDD & Supported Vector Data Descriptor \\
\hline SVM & Support Vector Machine \\
\hline TRPO & Trust Region Policy Optimization \\
\hline UAV & Unmanned Aerial Vehicle \\
\hline VR & Virtual Reality \\
\hline VUCA & Volatile, Uncertain, Complex, Ambiguous \\
\hline WGP & German Academic Society for Production Engineering \\
\hline XaaS & X-as-a-Service \\
\hline
\end{tabular}

\section{References}

1. Tao, F.; Cheng, J.; Qi, Q.; Zhang, M.; Zhang, H.; Sui, F. Digital twin-driven product design, manufacturing and service with big data. Int. J. Adv. Manuf. Technol. 2018, 94, 3563-3576. [CrossRef]

2. Scharl, S.; Praktiknjo, A. The Role of a Digital Industry 4.0 in a Renewable Energy System. Int. J. Energy Res. 2019, 43, 3891-3904. [CrossRef]

3. Wan, L.; Nochta, T.; Schooling, J.M. Developing a city-level digital twin-Propositions and a case study. In International Conference on Smart Infrastructure and Construction 2019 (ICSIC) Driving Data-Informed Decision-Making; ICE Publishing: London, UK, 2019; pp. 187-193. [CrossRef]

4. Shirowzhan, S.; Tan, W.; Sepasgozar, S.M. Digital twin and CyberGIS for improving connectivity and measuring the impact of infrastructure construction planning in smart cities. ISPRS Int. J. Geo-Inf. 2020, 9, 240. [CrossRef]

5. Lokuwaduge, C.S.D.S.; Heenetigala, K. Integrating Environmental, Social and Governance (ESG) Disclosure for a Sustainable Development: An Australian Study. Bus. Strategy Environ. 2017, 26, 438-450. [CrossRef]

6. Tao, F.; Zhang, H.; Liu, A.; Nee, A.Y. Digital Twin in Industry: State-of-the-Art. IEEE Trans. Ind. Inform. 2019, 15, $2405-2415$. [CrossRef]

7. Fuller, A.; Fan, Z.; Day, C.; Barlow, C. Digital Twin: Enabling Technologies, Challenges and Open Research. IEEE Access 2020, 8, 108952-108971. [CrossRef]

8. Jones, D.; Snider, C.; Nassehi, A.; Yon, J.; Hicks, B. Characterising the Digital Twin: A systematic literature review. CIRP J. Manuf. Sci. Technol. 2020, 29, 36-52. [CrossRef]

9. Lim, K.Y.H.; Zheng, P.; Chen, C.H. A state-of-the-art survey of Digital Twin: Techniques, engineering product lifecycle management and business innovation perspectives. J. Intell. Manuf. 2020, 31, 1313-1337. [CrossRef]

10. Liu, M.; Fang, S.; Dong, H.; Xu, C. Review of digital twin about concepts, technologies, and industrial applications. J. Manuf. Syst. 2020, 58, 346-361. [CrossRef] 
11. Sepasgozar, S.M.E. Differentiating Digital Twin from Digital Shadow: Elucidating a Paradigm Shift to Expedite a Smart, Sustainable Built Environment. Buildings 2021, 11, 151. [CrossRef]

12. Schleich, B.; Anwer, N.; Mathieu, L.; Wartzack, S. Shaping the digital twin for design and production engineering. CIRP Ann. 2017, 66, 141-144. [CrossRef]

13. Tao, F.; Sui, F.; Liu, A.; Qi, Q.; Zhang, M.; Song, B.; Guo, Z.; Lu, S.C.; Nee, A.Y. Digital twin-driven product design framework. Int J. Prod. Res. 2019, 57, 3935-3953. [CrossRef]

14. Rasheed, A.; San, O.; Kvamsdal, T. Digital twin: Values, challenges and enablers from a modeling perspective. IEEE Access 2020, 8, 21980-22012. [CrossRef]

15. Tao, F.; Zhang, M.; Liu, Y.; Nee, A.Y. Digital twin driven prognostics and health management for complex equipment. CIRP Ann. 2018, 67, 169-172. [CrossRef]

16. Glaessgen, E.H.; Stargel, D.S. The digital twin paradigm for future NASA and U.S. Air force vehicles. In Proceedings of the 53rd AIAA/ASME/ASCE/AHS/ASC Structures, Structural Dynamics and Materials Conference 20th AIAA/ASME/AHS Adaptive Structures Conference 14th AIAA, Honolulu, HI, USA, 23-26 April 2012,

17. Grieves, M.; Vickers, J. Digital Twin: Mitigating Unpredictable, Undesirable Emergent Behavior in Complex Systems. In Transdisciplinary Perspectives on Complex Systems: New Findings and Approaches; Kahlen, F.J., Flumerfelt, S., Alves, A., Eds.; Springer International Publishing: Cham, Switzerland, 2017; pp. 85-113. [CrossRef]

18. Grieves, M. Digital twin: Manufacturing excellence through virtual factory replication. White Pap. 2014, 1, 1-7.

19. Bauernhansl, T. WGP-Standpunkt Industrie 4.0; WGP, Wissenschaftliche Gesellschaft für Produktionstechnik: Darmstadt, Germany, 2016.

20. Wohlfeld, D.; Weiss, V.; Becker, B. Digital Shadow-From production to product. In 17 Internationales Stuttgarter Symposium; Bargende, M., Reuss, H.C., Wiedemann, J., Eds.; Springer Fachmedien Wiesbaden: Wiesbaden, Germany, 2017 ; pp. 783-794.

21. Bauernhansl, T.; Hartleif, S.; Felix, T. The Digital Shadow of production-A concept for the effective and efficient information supply in dynamic industrial environments. Procedia CIRP 2018, 72, 69-74. [CrossRef]

22. Riesener, M.; Schuh, G.; Dölle, C.; Tönnes, C. The digital shadow as enabler for data analytics in product life cycle management. Procedia CIRP 2019, 80, 729-734. [CrossRef]

23. West, T.D.; Pyster, A. Untangling the Digital Thread: The Challenge and Promise of Model-Based Engineering in Defense Acquisition. Insight 2015, 18, 45-55. [CrossRef]

24. Helu, M.; Hedberg, T. Enabling Smart Manufacturing Research and Development using a Product Lifecycle Test Bed. Procedia Manuf. 2015, 1, 86-97. [CrossRef]

25. Hedberg, T.; Lubell, J.; Fischer, L.; Maggiano, L.; Feeney, A.B. Testing the digital thread in support of model-based manufacturing and inspection. J. Comput. Inf. Sci. Eng. 2016, 16, 1-10. [CrossRef]

26. Brecher, C.; Epple, A.; Fey, M.; Königs, M.; Neus, S.; Wellmann, F.N. Lernende Produktionssysteme. In Proceedings of the Internet of Production für agile Unternehmen: AWK Aachener Werkzeugmaschinen-Kolloquium 2017, 18. bis 19. Mai/Christian Brecher, Fritz Klocke, Robert Schmitt, Günther Schuh, 29. Aachener Werkzeugmaschinen-Kolloquium, Aachen, Germany, 18-19 May 2017; Apprimus Verlag: Aachen, Germany, 2017; pp. 135-161.

27. Wagner, C.; Grothoff, J.; Epple, U.; Drath, R.; Malakuti, S.; Grüner, S.; Hoffmeister, M.; Zimermann, P. The role of the Industry 4.0 asset administration shell and the digital twin during the life cycle of a plant. In Proceedings of the 2017 22nd IEEE International Conference on Emerging Technologies and Factory Automation, Limassol, Cyprus, 12-15 September 2017; pp. 1-8. [CrossRef]

28. Monostori, L.; Kádár, B.; Bauernhansl, T.; Kondoh, S.; Kumara, S.; Reinhart, G.; Sauer, O.; Schuh, G.; Sihn, W.; Ueda, K. Cyber-physical systems in manufacturing. CIRP Ann. 2016, 65, 621-641. [CrossRef]

29. Jeschke, S.; Brecher, C.; Meisen, T.; Özdemir, D.; Eschert, T. Industrial Internet of Things and Cyber Manufacturing Systems. In Industrial Internet of Things; Springer Series in Wireless Technology; Jeschke, S., Brecher, C., Song, H., Rawat, D.B., Eds.; Number October in Springer Series in Wireless Technology; Springer International Publishing: Cham, Switzerland, 2017 ; pp. 3-19. [CrossRef]

30. Brecher, C.; Jeschke, S.; Schuh, G.; Aghassi, S.; Arnoscht, J.; Bauhoff, F.; Fuchs, S.; Jooß, C.; Karmann, O.; Kozielski, S.; et al. Integrative Production Technology for High-Wage Countries; Springer: Berlin/Heidelberg, Germany, 2012. [CrossRef]

31. Rosen, R.; Von Wichert, G.; Lo, G.; Bettenhausen, K.D. About the importance of autonomy and digital twins for the future of manufacturing. IFAC-PapersOnLine 2015, 28, 567-572. [CrossRef]

32. Qi, Q.; Tao, F. Digital Twin and Big Data Towards Smart Manufacturing and Industry 4.0: 360 Degree Comparison. IEEE Access 2018, 6, 3585-3593. [CrossRef]

33. Boos, W. Die Produktionswende-Turning Data into Sustainability. White Paper. 2021. Available online: https://www.wzl.rwthaachen.de/go/id/oixyt?\#aaaaaaaaaaojafx (accessed on 13 September 2021).

34. Helu, M.; Hedberg, T.; Barnard Feeney, A. Reference architecture to integrate heterogeneous manufacturing systems for the digital thread. CIRP J. Manuf. Sci. Technol. 2017, 19, 191-195. [CrossRef] [PubMed]

35. Zheng, Y.; Yang, S.; Cheng, H. An application framework of digital twin and its case study. J. Ambient Intell. Humaniz. Comput. 2019, 10, 1141-1153. [CrossRef]

36. Ding, K.; Chan, F.T.; Zhang, X.; Zhou, G.; Zhang, F. Defining a Digital Twin-based Cyber-Physical Production System for autonomous manufacturing in smart shop floors. Int. J. Prod. Res. 2019, 57, 6315-6334. [CrossRef] 
37. Tao, F.; Zhang, M. Digital Twin Shop-Floor: A New Shop-Floor Paradigm Towards Smart Manufacturing. IEEE Access 2017, 5, 20418-20427. [CrossRef]

38. Pennekamp, J.; Glebke, R.; Henze, M.; Meisen, T.; Quix, C.; Hai, R.; Gleim, L.; Niemietz, P.; Rudack, M.; Knape, S.; et al. Towards an infrastructure enabling the internet of production. In Proceedings of the 2019 IEEE International Conference on Industrial Cyber Physical Systems (ICPS), Taipei, Taiwan, 6-9 May 2019; pp. 31-37. [CrossRef]

39. May, M.C.; Schmidt, S.; Kuhnle, A.; Stricker, N.; Lanza, G. Product Generation Module: Automated Production Planning for optimized workload and increased efficiency in Matrix Production Systems. Procedia CIRP 2020, 96, 45-50. [CrossRef]

40. Roh, J.K.P. Assessing the Efficiency of Information Retrieval from the Digital Shadow at the Shop Floor using IT Assistive Systems. In Proceedings of the 16th Mechatronics Forum International Conference, Glasgow, UK, 19-21 September 2018; pp. 202-209.

41. Rebmann, A.; Knoch, S.; Emrich, A.; Fettke, P.; Loos, P. A multi-sensor approach for digital twins of manual assembly and commissioning. Procedia Manuf. 2020, 51, 549-556. [CrossRef]

42. Um, J.; Weyer, S.; Quint, F. Plug-and-Simulate within Modular Assembly Line enabled by Digital Twins and the use of AutomationML. IFAC-PapersOnLine 2017, 50, 15904-15909. [CrossRef]

43. Leng, J.; Liu, Q.; Ye, S.; Jing, J.; Wang, Y.; Zhang, C.; Zhang, D.; Chen, X. Digital twin-driven rapid reconfiguration of the automated manufacturing system via an open architecture model. Robot. Comput.-Integr. Manuf. 2020, 63, 101895. [CrossRef]

44. Feng, X.; Zhao, Z.; Zhang, C. Simulation optimization framework for online deployment and adjustment of reconfigurable machines in job shops. In Proceedings of the 2020 IEEE International Conference on Industrial Engineering and Engineering Management (IEEM), Singapore, 14-17 December 2020; pp. 731-735. [CrossRef]

45. Talkhestani, B.A.; Jazdi, N.; Schloegl, W.; Weyrich, M. Consistency check to synchronize the Digital Twin of manufacturing automation based on anchor points. Procedia CIRP 2018, 72, 159-164. [CrossRef]

46. Jazdi, N.; Ashtari Talkhestani, B.; Maschler, B.; Weyrich, M. Realization of AI-enhanced industrial automation systems using intelligent Digital Twins. Procedia CIRP 2021, 97, 396-400. [CrossRef]

47. Ma, X.; Cheng, J.; Qi, Q.; Tao, F. Artificial intelligence enhanced interaction in digital twin shop-floor. Procedia CIRP 2021, 100, 858-863. [CrossRef]

48. Cai, Y.; Starly, B.; Cohen, P.; Lee, Y.S. Sensor Data and Information Fusion to Construct Digital-twins Virtual Machine Tools for Cyber-physical Manufacturing. Procedia Manuf. 2017, 10, 1031-1042. [CrossRef]

49. Chhetri, S.R.; Faezi, S.; Canedo, A.; Faruque, M.A.A. QUILT: Quality inference from living digital twins in IoT-enabled manufacturing systems. In Proceedings of the 2019 Internet of Things Design and Implementation, Montreal, QC, Canada, 15-18 April 2019; pp. 237-248. [CrossRef]

50. Brecher, C.; Buchsbaum, M.; Storms, S. Control from the cloud: Edge computing, services and digital shadow for automation technologies. In Proceedings of the IEEE International Conference on Robotics and Automation, Montreal, QC, Canada, 20-24 May 2019; pp. 9327-9333. [CrossRef]

51. Biesinger, F.; Meike, D.; Kras, B.; Weyrich, M. A Case Study for a Digital Twin of Body-in-White Production Systems General Concept for Automated Updating of Planning Projects in the Digital Factory. In Proceedings of the IEEE International Conference on Emerging Technologies and Factory Automation, ETFA, Turin, Italy, 4-7 September 2018; pp. 19-26. [CrossRef]

52. Delisle, D.; Schreiber, M.; Krombholz, C.; Stüve, J. Production of fiber composite structures by means of cooperating robots. Lightweight Des. Worldw. 2018, 11, 42-47. [CrossRef]

53. Minos-Stensrud, M.; Haakstad, O.H.; Sakseid, O.; Westby, B.; Alcocer, A. Towards automated 3D reconstruction in SME factories and digital twin model generation. In Proceedings of the International Conference on Control, Automation and Systems, PyeongChang, Korea, 17-20 October 2018; pp. 1777-1781.

54. Hellmuth, R.; Wehner, F.; Giannakidis, A. Approach for an update method for digital factory models. Procedia CIRP 2020, 93, 280-285. [CrossRef]

55. Sommer, M.; Stjepandić, J.; Stobrawa, S.; von soden, M. Automatic generation of digital twin based on scanning and object recognition. Adv. Transdiscipl. Eng. 2019, 10, 645-654. [CrossRef]

56. Pan, Y.; Zhang, L. A BIM-data mining integrated digital twin framework for advanced project management. Autom. Constr. 2021, 124, 103564. [CrossRef]

57. Schuh, G.; Blum, M.; Reschke, J.; Birkmeier, M. Der digitale schatten in der auftragsabwicklung. ZWF Z. Fuer Wirtsch. Fabr. 2016, 111, 48-51. [CrossRef]

58. Fang, Y.; Peng, C.; Lou, P.; Zhou, Z.; Hu, J.; Yan, J. Digital-Twin-Based Job Shop Scheduling Toward Smart Manufacturing. IEEE Trans. Ind. Inform. 2019, 15, 6425-6435. [CrossRef]

59. Guo, H.; Chen, M.; Mohamed, K.; Qu, T.; Wang, S.; Li, J. A digital twin-based flexible cellular manufacturing for optimization of air conditioner line. J. Manuf. Syst. 2020, 58, 65-78. [CrossRef]

60. Zhang, M.; Tao, F.; Nee, A.Y. Digital Twin Enhanced Dynamic Job-Shop Scheduling. J. Manuf. Syst. 2020, 58, 146-156. [CrossRef]

61. Borangiu, T.; Oltean, E.; Răileanu, S.; Anton, F.; Anton, S.; Iacob, I. Embedded Digital Twin for ARTI-Type Control of Semicontinuous Production Processes. In International Workshop on Service Orientation in Holonic and Multi-Agent Manufacturing; Springer International Publishing: Charm, Switzerland, 2020; Volume 853, pp. 113-133._9. [CrossRef]

62. Zhang, K.; Qu, T.; Zhou, D.; Jiang, H.; Lin, Y.; Li, P.; Guo, H.; Liu, Y.; Li, C.; Huang, G.Q. Digital twin-based opti-state control method for a synchronized production operation system. Robot. Comput.-Integr. Manuf. 2020, 63, 101892. [CrossRef] 
63. Karanjkar, N.; Joglekar, A.; Mohanty, S.; Prabhu, V.; Raghunath, D.; Sundaresan, R. Digital twin for energy optimization in an SMT-PCB assembly line. In Proceedings of the 2018 IEEE International Conference on Internet of Things and Intelligence System, IOTAIS 2018, Bali, Indonesia, 1-3 November 2019; pp. 85-89. [CrossRef]

64. Leng, J.; Zhang, H.; Yan, D.; Liu, Q.; Chen, X.; Zhang, D. Digital twin-driven manufacturing cyber-physical system for parallel controlling of smart workshop. J. Ambient Intell. Humaniz. Comput. 2019, 10, 1155-1166. [CrossRef]

65. Guo, D.; Zhong, R.Y.; Lin, P.; Lyu, Z.; Rong, Y.; Huang, G.Q. Digital twin-enabled Graduation Intelligent Manufacturing System for fixed-position assembly islands. Robot. Comput.-Integr. Manuf. 2020, 63, 101917. [CrossRef]

66. Liu, Q.; Leng, J.; Yan, D.; Zhang, D.; Wei, L.; Yu, A.; Zhao, R.; Zhang, H.; Chen, X. Digital twin-based designing of the configuration, motion, control, and optimization model of a flow-type smart manufacturing system. J. Manuf. Syst. 2021, 58, 52-64. [CrossRef]

67. Wagner, R.; Haefner, B.; Lanza, G. Function-oriented quality control strategies for high precision products. Procedia CIRP 2018, 75, 57-62. [CrossRef]

68. Grégorio, J.L.; Lartigue, C.; Thiébaut, F.; Lebrun, R. A digital twin-based approach for the management of geometrical deviations during assembly processes. J. Manuf. Syst. 2020, 58, 108-117. [CrossRef]

69. Wunderlich, C.; Tschöpe, C.; Duckhorn, F. Advanced methods in NDE using machine learning approaches. AIP Conf. Proc. 2018, 1949. [CrossRef]

70. Polini, W.; Corrado, A. Digital twin of composite assembly manufacturing process. Int. J. Prod. Res. 2020, 58, 5238-5252. [CrossRef]

71. Schmitt, R.H.; Voigtmann, C. Sensor information as a service-component of networked production. J. Sens. Sens. Syst. 2018, 7, 389-402. [CrossRef]

72. Wagner, R.; Haefner, B.; Biehler, M.; Lanza, G. Digital DNA in quality control cycles of high-precision products. CIRP Ann. 2020, 69, 373-376. [CrossRef]

73. Schmitt, R.H.; Nienheysen, P.; Lehmann, N.; Jahangir, H.; Peterek, M.; Neuenhahn, T. Digitalized Ultrasonic Inspection by Optical Tracking. In Proceedings of the 2019 IEEE/SICE International Symposium on System Integration, SII 2019, Paris, France, 14-16 January 2019; pp. 566-571. [CrossRef]

74. Židek, K.; Modrák, V.; Pitel, J.; Šoltysová, Z. The digitization of quality control operations with cloud platform computing technologies. In Industry 4.0 for SMEs; Palgrave Macmillan: Cham, Switzerland, 2020; pp. 305-334.

75. Psarommatis, F. A generic methodology and a digital twin for zero defect manufacturing (ZDM) performance mapping towards design for ZDM. J. Manuf. Syst. 2021, 59, 507-521. [CrossRef]

76. Haße, H. Digital Twin for Real-Time Data Processing in Logistics. In Artificial Intelligence and Digital Transformation in Supply Chain Management, Proceedings of the Hamburg International Conference of Logistics (HICL), No. 27, Harmburg; epubli GmbH: Berlin, Germany, 26 September 2019.

77. Pan, Y.H.; Wu, N.Q.; Qu, T.; Li, P.Z.; Zhang, K.; Guo, H.F. Digital-twin-driven production logistics synchronization system for vehicle routing problems with pick-up and delivery in industrial park. Int. J. Comput. Integr. Manuf. 2020. [CrossRef]

78. Brenner, B.; Hummel, V. Digital Twin as Enabler for an Innovative Digital Shopfloor Management System in the ESB Logistics Learning Factory at Reutlingen-University. Procedia Manuf. 2017, 9, 198-205. [CrossRef]

79. Ivanov, D.; Dolgui, A. A digital supply chain twin for managing the disruption risks and resilience in the era of Industry 4.0. Prod. Plan. Control 2020, 1-14. [CrossRef]

80. Marmolejo-Saucedo, J.A. Design and Development of Digital Twins: A Case Study in Supply Chains. Mob. Netw. Appl. 2020, 25, 2141-2160. [CrossRef]

81. Cirullies, J.; Schwede, C. On-demand Shared Digital Twins-An Information Architectural Model to Create Transparency in Collaborative Supply Networks. In Proceedings of the 54th Hawaii International Conference on System Sciences, Honolulu, HI, USA, 5-8 January 2021; pp. 1675-1684. [CrossRef]

82. Tozanli, O.; Kongar, E.; Gupta, S.M. Evaluation of waste electronic product trade-in strategies in predictive twin disassembly systems in the era of blockchain. Sustainability 2020, 12, 5416. [CrossRef]

83. Wang, X.V.; Wang, L. Digital twin-based WEEE recycling, recovery and remanufacturing in the background of Industry 4.0. Int. J. Prod. Res. 2019, 57, 3892-3902. [CrossRef]

84. Wang, Y.; Wang, S.; Yang, B.; Zhu, L.; Liu, F. Big data driven Hierarchical Digital Twin Predictive Remanufacturing paradigm: Architecture, control mechanism, application scenario and benefits. J. Clean. Prod. 2020, 248, 119299. [CrossRef]

85. Hüttemann, G.; Buckhorst, A.F.; Schmitt, R.H. Modelling and assessing line-less mobile assembly systems. Procedia CIRP 2019, 81, 724-729. [CrossRef]

86. Rojek, I.; Mikołajewski, D.; Dostatni, E. Digital twins in product lifecycle for sustainability in manufacturing and maintenance. Appl. Sci. 2021, 11, 31. [CrossRef]

87. Hu, L.; Liu, Z.; Hu, W.; Wang, Y.; Tan, J.; Wu, F. Petri-net-based dynamic scheduling of flexible manufacturing system via deep reinforcement learning with graph convolutional network. J. Manuf. Syst. 2020, 55, 1-14. [CrossRef]

88. Negri, E.; Pandhare, V.; Cattaneo, L.; Singh, J.; Macchi, M.; Lee, J. Field-synchronized Digital Twin framework for production scheduling with uncertainty. J. Intell. Manuf. 2020, 32, 1207-1228. [CrossRef]

89. Rezaei Aderiani, A.; Wärmefjord, K.; Söderberg, R. Evaluating different strategies to achieve the highest geometric quality in self-adjusting smart assembly lines. Robot. Comput.-Integr. Manuf. 2021, 71, 102164. [CrossRef] 
90. Liu, Z.; Chen, W.; Zhang, C.; Yang, C.; Cheng, Q. Intelligent scheduling of a feature-process-machine tool supernetwork based on digital twin workshop. J. Manuf. Syst. 2020, 58, 157-167. [CrossRef]

91. Liu, Q.; Zhang, H.; Leng, J.; Chen, X. Digital twin-driven rapid individualised designing of automated flow-shop manufacturing system. Int. J. Prod. Res. 2019, 57, 3903-3919. [CrossRef]

92. Sun, X.; Bao, J.; Li, J.; Zhang, Y.; Liu, S.; Zhou, B. A digital twin-driven approach for the assembly-commissioning of high precision products. Robot. Comput.-Integr. Manuf. 2020, 61, 1-14. [CrossRef]

93. Singgih, I.K. Production Flow Analysis in a Semiconductor Fab Using Machine Learning Techniques. Processes 2021, 9, 407. [CrossRef]

94. Min, Q.; Lu, Y.; Liu, Z.; Su, C.; Wang, B. Machine Learning based Digital Twin Framework for Production Optimization in Petrochemical Industry. Int. J. Inf. Manag. 2019, 49, 502-519. [CrossRef]

95. Cronrath, C.; Aderiani, A.R.; Lennartson, B. Enhancing digital twins through reinforcement learning. In Proceedings of the IEEE International Conference on Automation Science and Engineering, Vancouver, BC, Canada, 22-26 August 2019; pp. 293-298. [CrossRef]

96. Jaensch, F.; Csiszar, A.; Kienzlen, A.; Verl, A. Reinforcement learning of material flow control logic using hardware-in-the-loop simulation. In Proceedings of the 2018 1st IEEE International Conference on Artificial Intelligence for Industries, AI4I 2018, Laguna Hills, CA, USA, 26-28 September 2019; pp. 77-80. [CrossRef]

97. Waschneck, B.; Reichstaller, A.; Belzner, L.; Altenmüller, T.; Bauernhansl, T.; Knapp, A.; Kyek, A. Optimization of global production scheduling with deep reinforcement learning. Procedia CIRP 2018, 72, 1264-1269. [CrossRef]

98. Wang, T.; Cheng, J.; Yang, Y.; Esposito, C.; Snoussi, H.; Tao, F. Adaptive Optimization Method in Digital Twin Conveyor Systems via Range-Inspection Control. IEEE Trans. Autom. Sci. Eng. 2020, 1-9. [CrossRef]

99. Kuhnle, A.; Kaiser, J.P.; Theiß, F.; Stricker, N.; Lanza, G. Designing an adaptive production control system using reinforcement learning. J. Intell. Manuf. 2020, 32, 855-876. [CrossRef]

100. May, M.C.; Overbeck, L.; Wurster, M.; Kuhnle, A.; Lanza, G. Foresighted digital twin for situational agent selection in production control. Procedia CIRP 2021, 99, 27-32. [CrossRef]

101. Li, L.; Liu, D.; Liu, J.; Zhou, H.G.; Zhou, J. Quality prediction and control of assembly and welding process for ship group product based on digital twin. Scanning 2020, 2020, 3758730. [CrossRef] [PubMed]

102. Yacob, F.; Semere, D.; Nordgren, E. Anomaly detection in Skin Model Shapes using machine learning classifiers. Int. J. Adv. Manuf. Technol. 2019, 105, 3677-3689. [CrossRef]

103. Alexopoulos, K.; Nikolakis, N.; Chryssolouris, G. Digital twin-driven supervised machine learning for the development of artificial intelligence applications in manufacturing. Int. J. Comput. Integr. Manuf. 2020, 33, 429-439. [CrossRef]

104. Zhou, G.; Zhang, C.; Li, Z.; Ding, K.; Wang, C. Knowledge-driven digital twin manufacturing cell towards intelligent manufacturing. Int. J. Prod. Res. 2020, 58, 1034-1051. [CrossRef]

105. Zheng, Y.; Wang, S.; Li, Q.; Li, B. Fringe projection profilometry by conducting deep learning from its digital twin. Opt. Express 2020, 28, 36568. [CrossRef] [PubMed]

106. Zhao, Z.; Shen, L.; Yang, C.; Wu, W.; Zhang, M.; Huang, G.Q. IoT and digital twin enabled smart tracking for safety management. Comput. Oper. Res. 2021, 128, 105183. [CrossRef]

107. Busch, M.; Schuh, G.; Kelzenberg, C.; De Lange, J. Development of production planning and control through the empowerment of artificial intelligence. In Proceedings of the 2019 2nd International Conference on Artificial Intelligence for Industries, AI4I 2019, Laguna Hills, CA, USA, 25-27 September 2019; pp. 115-118. [CrossRef]

108. Guo, F.; Zou, F.; Liu, J.; Wang, Z. Working mode in aircraft manufacturing based on digital coordination model. Int. J. Adv. Manuf. Technol. 2018, 98, 1547-1571. [CrossRef]

109. Zhang, C.; Zhou, G.; Hu, J.; Li, J. Deep learning-enabled intelligent process planning for digital twin manufacturing cell. Knowl.-Based Syst. 2020, 191, 105247. [CrossRef]

110. Jaensch, F.; Csiszar, A.; Scheifele, C.; Verl, A. Digital Twins of Manufacturing Systems as a Base for Machine Learning. In Proceedings of the 2018 25th International Conference on Mechatronics and Machine Vision in Practice, M2VIP 2018, Stuttgart, Germany, 20-22 November 2019. [CrossRef]

111. Delbrügger, T.; Rossmann, J. Representing adaptation options in experimentable digital twins of production systems. Int. J. Comput. Integr. Manuf. 2019, 32, 352-365. [CrossRef]

112. Delbrügger, T.; Meißner, M.; Wirtz, A.; Biermann, D.; Myrzik, J.; Rossmann, J.; Wiederkehr, P. Multi-level simulation concept for multidisciplinary analysis and optimization of production systems. Int. J. Adv. Manuf. Technol. 2019, 103, 3993-4012. [CrossRef]

113. Meierhofer, J.; West, S.; Rapaccini, M.; Barbieri, C. The Digital Twin as a Service Enabler: From the Service Ecosystem to the Simulation Model. In Lecture Notes in Business Information Processing; Springer International Publishing: Porto, Portugal, 2020; Volume 377 LNBIP, pp. 347-359._25. [CrossRef]

114. Li, X.; Cao, J.; Liu, Z.; Luo, X. Sustainable Business Model Based on Digital Twin Platform Network: The Inspiration from Haier's Case Study in China. Sustainability 2020, 12, 936. [CrossRef]

115. Kampker, A.; Stich, V.; Jussen, P.; Moser, B.; Kuntz, J. Business models for industrial smart services-the example of a digital twin for a product-service-system for potato harvesting. Procedia CIRP 2019, 83, 534-540. [CrossRef]

116. Xi, T.; Benincá, I.M.; Kehne, S.; Fey, M.; Brecher, C. Tool wear monitoring in roughing and finishing processes based on machine internal data. Int. J. Adv. Manuf. Technol. 2021, 113, 3543-3554. [CrossRef] 
117. Botkina, D.; Hedlind, M.; Olsson, B.; Henser, J.; Lundholm, T. Digital Twin of a Cutting Tool. Procedia CIRP 2018, 72, 215-218. [CrossRef]

118. Mi, S.; Feng, Y.; Zheng, H.; Wang, Y.; Gao, Y.; Tan, J. Prediction maintenance integrated decision-making approach supported by digital twin-driven cooperative awareness and interconnection framework. J. Manuf. Syst. 2020, 58, 329-345. [CrossRef]

119. Luo, W.; Hu, T.; Zhang, C.; Wei, Y. Digital twin for CNC machine tool: Modeling and using strategy. J. Ambient Intell. Humaniz. Comput. 2019, 10, 1129-1140. [CrossRef]

120. Aivaliotis, P.; Georgoulias, K.; Chryssolouris, G. The use of Digital Twin for predictive maintenance in manufacturing. Int. J. Comput. Integr. Manuf. 2019, 32, 1067-1080. [CrossRef]

121. He, B.; Liu, L.; Zhang, D. Digital Twin-driven Remaining Useful Life Prediction for Gear Performance Degradation: A Review. J. Comput. Inf. Sci. Eng. 2021, 21, 030801. [CrossRef]

122. Bergs, C.; Heizmann, M.; Hartmann, D.; Carillo, G.L. Novel method for online wear estimation of centrifugal pumps using multi-fidelity modeling. In Proceedings of the 2019 IEEE International Conference on Industrial Cyber Physical Systems, ICPS 2019, Taipei, Taiwan, 6-9 May 2019; pp. 185-190. [CrossRef]

123. Zhang, M.; Zuo, Y.; Tao, F. Equipment Energy Consumption Management in Applications. In Proceedings of the 2018 IEEE 15 th International Conference on Networking, Sensing and Control (ICNSC), Zhuhai, China, 27-29 March 2018; pp. 1-5.

124. Blume, C.; Blume, S.; Thiede, S.; Herrmann, C. Data-driven digital twins for technical building services operation in factories: A cooling tower case study. J. Manuf. Mater. Process. 2020, 4, 97. [CrossRef]

125. Surico, M.; Ricatto, R.; Merlo, A.; Németh, I.; Sardelis, A.; Villoslada, M.; Montejo, E.; Frenkel, N.; Aivaliotis, P.; de la Pera Celada, I.; et al. PROGRAMS project approach to maintenance management. IFAC-PapersOnLine 2020, 53, 313-318. [CrossRef]

126. Lynn, R.; Sati, M.; Tucker, T.; Rossignac, J.; Saldana, C.; Kurfess, T. Realization of the 5-Axis Machine Tool Digital Twin Using Direct Servo Control from CAM. National Institute of Standards and Technology (NIST) Model-Based Enterprise Summit; Advanced Manufacturing Series (NIST AMS): Gaithersburg, MD, USA, 2018; pp. 1-22.

127. $\mathrm{Xu}, \mathrm{J}$; Guo, T. Application and research on digital twin in electronic cam servo motion control system. Int. J. Adv. Manuf. Technol. 2021, 112, 1145-1158. [CrossRef]

128. Wagg, D.J.; Worden, K.; Barthorpe, R.J.; Gardner, P. Digital Twins: State-of-The-Art and Future Directions for Modeling and Simulation in Engineering Dynamics Applications. ASCE-ASME J. Risk Uncertain. Eng. Syst. Part B Mech. Eng. 2020, 6, 1-17. [CrossRef]

129. Huynh, H.N.; Altintas, Y. Modeling the Dynamics of Five-Axis Machine Tool Using the Multibody Approach. J. Manuf. Sci. Eng. 2021, 143, 021012. [CrossRef]

130. Wang, J.; Ye, L.; Gao, R.X.; Li, C.; Zhang, L. Digital Twin for rotating machinery fault diagnosis in smart manufacturing. Int. J. Prod. Res. 2019, 57, 3920-3934. [CrossRef]

131. Tseng, G.W.G.; Chen, C.Q.G.; Erkorkmaz, K.; Engin, S. Digital shadow identification from feed drive structures for virtual process planning. CIRP J. Manuf. Sci. Technol. 2019, 24, 55-65. [CrossRef]

132. Wang, C.P.; Erkorkmaz, K.; McPhee, J.; Engin, S. In-process digital twin estimation for high-performance machine tools with coupled multibody dynamics. CIRP Ann. 2020, 69, 321-324. [CrossRef]

133. Königs, M.; Wellmann, F.; Wiesch, M.; Epple, A.; Brecher, C.; Schmitt, R.; Schuh, G. A scalable, hybrid learning approach to process-parallel estimation of cutting forces in milling applications. Robert Schmitt Günther Schuh (Publ.) 2017, 7, 425-432.

134. Su, S.; Zhao, G.; Xiao, W.; Yang, Y.; Cao, X. An image-based approach to predict instantaneous cutting forces using convolutional neural networks in end milling operation. Int. J. Adv. Manuf. Technol. 2021, 115, 1657-1669. [CrossRef]

135. Yiping, G.; Xinyu, L.; Gao, L. A Deep Lifelong Learning Method for Digital-Twin Driven Defect Recognition With Novel Classes. J. Comput. Inf. Sci. Eng. 2021, 21, 031004. [CrossRef]

136. Wang, Z.; Liu, Q.; Chen, H.; Chu, X. A deformable CNN-DLSTM based transfer learning method for fault diagnosis of rolling bearing under multiple working conditions. Int. J. Prod. Res. 2020, 59, 4811-4825. [CrossRef]

137. Zotov, E.; Tiwari, A.; Kadirkamanathan, V. Towards a Digital Twin with Generative Adversarial Network Modelling of Machining Vibration. In International Conference on Engineering Applications of Neural Networks; Springer International Publishing: Cham, Switzerland, 2020; pp. 190-201._14. [CrossRef]

138. Alguri, K.S.; Chia, C.C.; Harley, J.B. Sim-to-Real: Employing ultrasonic guided wave digital surrogates and transfer learning for damage visualization. Ultrasonics 2021, 111, 106338. [CrossRef]

139. Autiosalo, J.; Ala-Laurinaho, R.; Mattila, J.; Valtonen, M.; Peltoranta, V.; Tammi, K. Towards integrated digital twins for industrial products: Case study on an overhead crane. Appl. Sci. 2021, 11, 683. [CrossRef]

140. Leser, P.E.; Warner, J.E.; Leser, W.P.; Bomarito, G.F.; Newman, J.A.; Hochhalter, J.D. A digital twin feasibility study (Part II): Non-deterministic predictions of fatigue life using in-situ diagnostics and prognostics. Eng. Fract. Mech. 2020, $229,106903$. [CrossRef]

141. Cattaneo, L.; MacChi, M. A Digital Twin Proof of Concept to Support Machine Prognostics with Low Availability of Run-To-Failure Data. IFAC-PapersOnLine 2019, 52, 37-42. [CrossRef]

142. Luo, W.; Hu, T.; Ye, Y.; Zhang, C.; Wei, Y. A hybrid predictive maintenance approach for CNC machine tool driven by Digital Twin. Robot. Comput.-Integr. Manuf. 2020, 65, 101974. [CrossRef]

143. Qiao, Q.; Wang, J.; Ye, L.; Gao, R.X. Digital twin for machining tool condition prediction. Procedia CIRP 2019, 81, 1388-1393. [CrossRef] 
144. Wang, P.; Luo, M. A digital twin-based big data virtual and real fusion learning reference framework supported by industrial internet towards smart manufacturing. J. Manuf. Syst. 2021, 58, 16-32. [CrossRef]

145. Xie, N.; Kou, R.; Yao, Y. Tool condition prognostic model based on digital twin system. Procedia CIRP 2020, 93, 1502-1507. [CrossRef]

146. Anis, M.D.; Taghipour, S.; Lee, C.G. Optimal RUL estimation: A state-of-art digital twin application. In Proceedings of the Annual Reliability and Maintainability Symposium, Palm Springs, CA, USA, 27-30 January 2020. [CrossRef]

147. Ladj, A.; Wang, Z.; Meski, O.; Belkadi, F.; Ritou, M.; Da Cunha, C. A knowledge-based Digital Shadow for machining industry in a Digital Twin perspective. J. Manuf. Syst. 2020, 58, 168-179. [CrossRef]

148. Zhang, X.; Liu, L.; Wan, X.; Feng, B. Tool Wear Online Monitoring Method Based on DT and SSAE-PHMM. J. Comput. Inf. Sci. Eng. 2021, 21, 034501. [CrossRef]

149. Xu, Y.; Sun, Y.; Liu, X.; Zheng, Y. A Digital-Twin-Assisted Fault Diagnosis Using Deep Transfer Learning. IEEE Access 2019, 7, 19990-19999. [CrossRef]

150. Booyse, W.; Wilke, D.N.; Heyns, S. Deep digital twins for detection, diagnostics and prognostics. Mech. Syst. Signal Process. 2020, 140, 106612. [CrossRef]

151. Kaji, M.; Parvizian, J.; van de Venn, H.W. Constructing a reliable health indicator for bearings using convolutional autoencoder and continuous wavelet transform. Appl. Sci. 2020, 10, 8948. [CrossRef]

152. Salvador Palau, A.; Dhada, M.H.; Parlikad, A.K. Multi-agent system architectures for collaborative prognostics. J. Intell. Manuf. 2019, 30, 2999-3013. [CrossRef]

153. Karve, P.M.; Guo, Y.; Kapusuzoglu, B.; Mahadevan, S.; Haile, M.A. Digital twin approach for damage-tolerant mission planning under uncertainty. Eng. Fract. Mech. 2020, 225, 106766. [CrossRef]

154. Kabaldin, Y.G.; Shatagin, D.A.; Anosov, M.S.; Kolchin, P.V.; Kuz'mishina, A.M. CNC Machine Tools and Digital Twins. Russ. Eng. Res. 2019, 39, 637-644. [CrossRef]

155. Simon, G.; Hantos, G.B.; Patel, M.S.; Tweedie, A.; Harvey, G. Machine Learning Enabled FBAR Digital Twin for Rapid Optimization. In Proceedings of the IEEE International Ultrasonics Symposium, IUS, Las Vegas, NV, USA, 7-11 September 2020; pp. 33-36. doi:10.1109/IUS46767.2020.9251797. [CrossRef]

156. Chakraborty, S.; Adhikari, S.; Ganguli, R. The role of surrogate models in the development of digital twins of dynamic systems. Appl. Math. Model. 2021, 90, 662-681. [CrossRef]

157. Gardner, P.; Dal Borgo, M.; Ruffini, V.; Hughes, A.J.; Zhu, Y.; Wagg, D.J. Towards the Development of an Operational Digital Twin. Vibration 2020, 3, 235-265. [CrossRef]

158. Haber, R.; Strzelczak, S.; Miljkovic, Z.; Castano, F.; Fumagalli, L.; Petrovic, M. Digital twin-based Optimization on the basis of Grey Wolf Method. A Case Study on Motion Control Systems. In Proceedings of the 2020 IEEE Conference on Industrial Cyberphysical Systems, ICPS 2020, Tampere, Finland, 10-12 June 2020; pp. 469-474. [CrossRef]

159. Chakraborty, S.; Adhikari, S. Machine learning based digital twin for dynamical systems with multiple time-scales. Comput. Struct. 2021, 243, 106410. [CrossRef]

160. He, B.; Li, T.; Xiao, J. Digital twin-driven controller tuning method for dynamics. J. Comput. Inf. Sci. Eng. 2021, 21, 031010. [CrossRef]

161. Hartmann, D.; Herz, M.; Wever, U. Model Order Reduction a Key Technology for Digital Twins. In Reduced-Order Modeling (ROM) for Simulation and Optimization: Powerful Algorithms as Key Enablers for Scientific Computing; Keiper, W., Milde, A., Volkwein, S., Eds.; Springer International Publishing: Cham, Switzerland, 2018; pp. 167-179._8. [CrossRef]

162. Podskarbi, M.; Knezevic, D.J. Digital twin for operations-present applications and future digital thread. In Proceedings of the Annual Offshore Technology Conference, Houston, TX, USA, 6 May 2020; pp. 4-7. [CrossRef]

163. Zambrano, V.; Rodríguez-Barrachina, R.; Calvo, S.; Izquierdo, S. TWINKLE: A digital-twin-building kernel for real-time computer-aided engineering. SoftwareX 2020, 11, 100419. [CrossRef]

164. Kehl, P.; Lange, D.; Konstantin Maurer, F.; Nemeth, G.; Overbeck, D.; Jung, S.; Konig, N.; Schmitt, R.H. Comparison of 5G Enabled Control Loops for Production. In Proceedings of the 2020 IEEE 31st Annual International Symposium on Personal, Indoor and Mobile Radio Communications, London, UK, 31 August-3 September 2020; pp. 1-6. [CrossRef]

165. Digital Twins in Product Life Cycles. Available online: https:/ / www.vernetzte-adaptive-produktion.de/en/technology-trends/ digital-twin.html (accessed on 13 September 2021).

166. Königs, M.; Brecher, C. Process-parallel virtual quality evaluation for metal cutting in series production. Procedia Manuf. 2018, 26, 1087-1093. [CrossRef]

167. Brecher, C.; Eckel, H.M.; Motschke, T.; Fey, M.; Epple, A. Estimation of the virtual workpiece quality by the use of a spindleintegrated process force measurement. CIRP Ann. 2019, 68, 381-384. [CrossRef]

168. Denkena, B.; Pape, O.; Krödel, A.; Böß, V.; Ellersiek, L.; Mücke, A. Process design for 5-axis ball end milling using a real-time capable dynamic material removal simulation. Prod. Eng. 2021, 15, 89-95. [CrossRef]

169. Afrasiabi, M.; Meier, L.; Röthlin, M.; Klippel, H.; Wegener, K. GPU-accelerated meshfree simulations for parameter identification of a friction model in metal machining. Int. J. Mech. Sci. 2020, 176, 105571. [CrossRef]

170. Cao, X.; Zhao, G.; Xiao, W. Digital Twin-oriented real-time cutting simulation for intelligent computer numerical control machining. Proc. Inst. Mech. Eng. Part B J. Eng. Manuf. 2020. [CrossRef] 
171. Hänel, A.; Schnellhardt, T.; Wenkler, E.; Nestler, A.; Brosius, A.; Corinth, C.; Fay, A.; Ihlenfeldt, S. The development of a digital twin for machining processes for the application in aerospace industry. Procedia CIRP 2020, 93, 1399-1404. [CrossRef]

172. Tong, X.; Liu, Q.; Pi, S.; Xiao, Y. Real-time machining data application and service based on IMT digital twin. J. Intell. Manuf. 2020, 31, 1113-1132. [CrossRef]

173. Armendia, M.; Cugnon, F.; Berglind, L.; Ozturk, E.; Gil, G.; Selmi, J. Evaluation of machine tool digital twin for machining operations in industrial environment. Procedia CIRP 2019, 82, 231-236. [CrossRef]

174. Brecher, C.; Wetzel, A.; Berners, T.; Epple, A. Increasing productivity of cutting processes by real-time compensation of tool deflection due to process forces. J. Mach. Eng. 2019, 19, 16-27. [CrossRef]

175. Ward, R.; Sencer, B.; Jones, B.; Ozturk, E. Accurate prediction of machining feedrate and cycle times considering interpolator dynamics. Int. J. Adv. Manuf. Technol. 2021, 116, 417-438. [CrossRef]

176. Heo, E.; Yoo, N. Numerical Control Machine Optimization Technologies through Analysis of Machining History Data Using Digital Twin. Appl. Sci. 2021, 11, 3259. [CrossRef]

177. Brecher, C.; Wiesch, M.; Wellmann, F. Productivity Increase-Model-based optimisation of NC-controlled milling processes to reduce machining time and improve process quality. IFAC-PapersOnLine 2019, 52, 1803-1807. [CrossRef]

178. Söderberg, R.; Wärmefjord, K.; Madrid, J.; Lorin, S.; Forslund, A.; Lindkvist, L. An information and simulation framework for increased quality in welded components. CIRP Ann. 2018, 67, 165-168. [CrossRef]

179. Papacharalampopoulos, A.; Stavropoulos, P.; Petrides, D. Towards a digital twin for manufacturing processes: Applicability on laser welding. Procedia CIRP 2020, 88, 110-115. [CrossRef]

180. Loaldi, D.; Regi, F.; Baruffi, F.; Calaon, M.; Quagliotti, D.; Zhang, Y.; Tosello, G. Experimental validation of injection molding simulations of 3D microparts and microstructured components using virtual design of experiments and multi-scale modeling. Micromachines 2020, 11, 614. [CrossRef]

181. Bibow, P.; Dalibor, M.; Hopmann, C.; Mainz, B.; Rumpe, B.; Schmalzing, D.; Schmitz, M.; Wortmann, A. Model-Driven Development of a Digital Twin for Injection Molding. In Advanced Information Systems Engineering; Dustdar, S., Yu, E., Salinesi, C., Rieu, D., Pant, V., Eds.; Springer International Publishing: Cham, Switzerland, 2020; pp. 85-100.

182. Weigelt, M.; Kink, J.; Mayr, A.; Lindenfels, J.V.; Kuhl, A.; Franke, J. Digital twin of the linear winding process based on explicit finite element method. In Proceedings of the 2019 9th International Electric Drives Production Conference, EDPC 2019_Proceedings, Esslingen, Germany, 3-4 December 2019. [CrossRef]

183. Schulz, M.; Janssen, H.; Brecher, C. A Digital Shadow for the Infrared-based Tape Laying Process of Tailored Blanks out of Thermoplastic Unidirectional Tape. Procedia CIRP 2020, 85, 221-226. [CrossRef]

184. Havinga, J.; Mandal, P.K.; van den Boogaard, T. Exploiting data in smart factories: Real-time state estimation and model improvement in metal forming mass production. Int. J. Mater. Form. 2020, 13, 663-673. [CrossRef]

185. Bordatchev, E.; Cvijanovic, S.; Tutunea-Fatan, O.R. Effect of initial surface topography during laser polishing process: Statistical analysis. Procedia Manuf. 2019, 34, 269-274. [CrossRef]

186. Zambal, S.; Eitzinger, C.; Clarke, M.; Klintworth, J.; Mechin, P.y. Effects of defects analysis based on manufacturing data. In Proceedings of the 2018 IEEE 16th International Conference on Industrial Informatics (INDIN), Porto, Portugal, 18-20 July 2018; pp. 803-808.

187. Görthofer, J.; Meyer, N.; Pallicity, T.D.; Schöttl, L.; Trauth, A.; Schemmann, M.; Hohberg, M.; Pinter, P.; Elsner, P.; Henning, F.; et al. Virtual process chain of sheet molding compound: Development, validation and perspectives. Compos. Part B Eng. 2019, 169, 133-147. [CrossRef]

188. Moretti, M.; Rossi, A.; Senin, N. In-process monitoring of part geometry in fused filament fabrication using computer vision and digital twins. Addit. Manuf. 2021, 37, 101609. [CrossRef]

189. Huang, H.; Ma, N.; Chen, J.; Feng, Z.; Murakawa, H. Toward large-scale simulation of residual stress and distortion in wire and arc additive manufacturing. Addit. Manuf. 2020, 34, 101248. [CrossRef]

190. Reisch, R.; Hauser, T.; Kamps, T.; Knoll, A. Robot based wire arc additive manufacturing system with context-sensitive multivariate monitoring framework. Procedia Manuf. 2020, 51, 732-739. [CrossRef]

191. Ünal-Saewe, T.; Vedder, C.; Vervoort, S.; Schleifenbaum, J.H. Digitaler Zwilling im Produktlebenszyklus additiv gefertigter Komponenten. In Handbuch Industrie 4.0: Recht, Technik, Gesellschaft; Frenz, W., Ed.; Springer: Berlin/Heidelberg, Germany, 2020; pp. 591-602._30. [CrossRef]

192. Heo, T.W.; Khairallah, S.A.; Shi, R.; Berry, J.; Perron, A.; Calta, N.P.; Martin, A.A.; Barton, N.R.; Roehling, J.D.; Roehling, T.; et al. A mesoscopic digital twin that bridges length and time scales for control of additively manufactured metal microstructures. $J$. Phys. Mater. 2021, 4, 034012. [CrossRef]

193. Ertveldt, J.; Guillaume, P.; Helsen, J. MiCLAD as a platform for real-time monitoring and machine learning in laser metal deposition. Procedia CIRP 2020, 94, 456-461. [CrossRef]

194. Bayer, B.; Diaz, R.D.; Melcher, M.; Striedner, G.; Duerkop, M. Digital twin application for model-based doe to rapidly identify ideal process conditions for space-time yield optimization. Processes 2021, 9, 1109. [CrossRef]

195. Zhao, Z.; Wang, S.; Wang, Z.; Wang, S.; Ma, C.; Yang, B. Surface roughness stabilization method based on digital twin-driven machining parameters self-adaption adjustment: A case study in five-axis machining. J. Intell. Manuf. 2020, 1-10. [CrossRef]

196. Samnejad, M.; Shirangi, M.G.; Ettehadi, R. A digital twin of drilling fluids rheology for real-time rig operations. In Proceedings of the Annual Offshore Technology Conference, Houston, TX, USA, 4 May 2020; pp. 4-7. [CrossRef] 
197. Repalle, N.; Thethi, R.; Viana, P.; Tellier, E. Application of machine learning for fatigue prediction of flexible risers-Digital twin approach. In Proceedings of the SPE Asia Pacific Oil \& Gas Conference and Exhibition, online, 12 November 2020. [CrossRef]

198. Ghosh, A.K.; Sharif Ullah, A.M.; Kubo, A.; Akamatsu, T.; D'Addona, D.M. Machining phenomenon twin construction for industry 4.0: A case of surface roughness. J. Manuf. Mater. Process. 2020, 4, 11. [CrossRef]

199. Zhou, Y.; Xing, T.; Song, Y.; Li, Y.; Zhu, X.; Li, G.; Ding, S. Digital-twin-driven geometric optimization of centrifugal impeller with free-form blades for five-axis flank milling. J. Manuf. Syst. 2021, 58, 22-35. [CrossRef]

200. Hardt, M.; Schraknepper, D.; Bergs, T. Investigations on the Application of the Downhill-Simplex-Algorithm to the Inverse Determination of Material Model Parameters for FE-Machining Simulations. Simul. Model. Pract. Theory 2021, 107, 129-148. [CrossRef]

201. Gaikwad, A.; Yavari, R.; Montazeri, M.; Cole, K.; Bian, L.; Rao, P. Toward the digital twin of additive manufacturing: Integrating thermal simulations, sensing, and analytics to detect process faults. IISE Trans. 2020, 52, 1204-1217. [CrossRef]

202. Gaikwad, A.; Giera, B.; Guss, G.M.; Forien, J.B.; Matthews, M.J.; Rao, P. Heterogeneous sensing and scientific machine learning for quality assurance in laser powder bed fusion-A single-track study. Addit. Manuf. 2020, 36, 101659. [CrossRef]

203. Ko, H.; Witherell, P.; Ndiaye, N.Y.; Lu, Y. Machine learning based continuous knowledge engineering for additive manufacturing. In Proceedings of the IEEE International Conference on Automation Science and Engineering, Vancouver, BC, Canada, 22-26 August 2019; pp. 648-654. [CrossRef]

204. Stavropoulos, P.; Papacharalampopoulos, A.; Athanasopoulou, L. A molecular dynamics based digital twin for ultrafast laser material removal processes. Int. J. Adv. Manuf. Technol. 2020, 108, 413-426. [CrossRef]

205. Stojanovic, N.; Milenovic, D. Data-driven Digital Twin approach for process optimization: An industry use case. In Proceedings of the 2018 IEEE International Conference on Big Data, Big Data 2018, Seattle, WA, USA, 10-13 December 2019; pp. $4202-4211$. [CrossRef]

206. Stieber, S.; Hoffmann, A.; Schiendorfer, A.; Reif, W.; Beyrle, M.; Faber, J.; Richter, M.; Sause, M. Towards Real-time Process Monitoring and Machine Learning for Manufacturing Composite Structures. In Proceedings of the IEEE International Conference on Emerging Technologies and Factory Automation, ETFA, Vienna, Austria, 8-11 September 2020; pp. 1455-1458. [CrossRef]

207. Hürkamp, A.; Gellrich, S.; Ossowski, T.; Beuscher, J.; Thiede, S.; Herrmann, C.; Dröder, K. Combining simulation and machine learning as digital twin for the manufacturing of overmolded thermoplastic composites. J. Manuf. Mater. Process. $2020,4,92$. [CrossRef]

208. Pfrommer, J.; Zimmerling, C.; Liu, J.; Kärger, L.; Henning, F.; Beyerer, J. Optimisation of manufacturing process parameters using deep neural networks as surrogate models. Procedia CIRP 2018, 72, 426-431. [CrossRef]

209. Ghanem, R.; Soize, C.; Mehrez, L.; Aitharaju, V. Probabilistic learning and updating of a digital twin for composite material systems. Int. J. Numer. Methods Eng. 2020, 1-17. [CrossRef]

210. Chen, Y.W.; Joseph, R.J.; Kanyuck, A.; Khan, S.; Malhan, R.K.; Manyar, O.M.; McNulty, Z.; Wang, B.; Barbič, J.; Gupta, S.K. A Digital Twin for Automated Layup of Prepreg Composite Sheets. In Volume 1: Additive Manufacturing; Advanced Materials Manufacturing; Biomanufacturing; Life Cycle Engineering; Manufacturing Equipment and Automation; American Society of Mechanical Engineers: New York, NY, USA, 2021; doi:10.1115/MSEC2021-63900. [CrossRef]

211. Asadi, M.; Mohseni, M.; Golkhosh, F.; Kashani, M.T.; Fernandez, M.; Smith, M. A Hybrid Digital-Twin Platform for Sequence Design in Welded Structures. In Proceedings of the ASME 2020 Pressure Vessel \& Piping Conference PVP2020, Minneapolis, MN, USA, 19-24 June 2020; pp. 1-10.

212. Ktari, A.; El Mansori, M. Digital twin of functional gating system in 3D printed molds for sand casting using a neural network. J. Intell. Manuf. 2020, 1-13. [CrossRef]

213. Denkena, B.; Dahlmann, D.; Boujnah, H. Tool Deflection Control by a Sensory Spindle Slide for Milling Machine Tools. Procedia CIRP 2017, 62, 329-334. [CrossRef]

214. Min, S.H.; Lee, T.H.; Lee, G.Y.; Zontar, D.; Brecher, C.; Ahn, S.H. Directly printed low-cost nanoparticle sensor for vibration measurement during milling process. Materials 2020, 13, 2920. [CrossRef]

215. Postel, M.; Aslan, D.; Wegener, K.; Altintas, Y. Monitoring of vibrations and cutting forces with spindle mounted vibration sensors. CIRP Ann. 2019, 68, 413-416. [CrossRef]

216. Mayes, A.; Heffernan, J.; Jauriqui, L.; Livings, R.; Biedermann, E.; Aldrin, J.C.; Goodlet, B.R.; Mazdiyasni, S. Process compensated resonance testing (PCRT) inversion for material characterization and digital twin calibration. AIP Conf. Proc. $2019,2102$. [CrossRef]

217. Schäkel, M.; McNab, J.; Dodds, N.; Peters, T.; Janssen, H.; Brecher, C. Data collection and analysis for the creation of a digital shadow during the production of thermoplastic composite layers in unbonded flexible pipes. Proc. Int. Conf. Offshore Mech. Arct. Eng. 2018, 5, 1-9. [CrossRef]

218. Kwon, S.; Monnier, L.V.; Barbau, R.; Bernstein, W.Z. Enriching standards-based digital thread by fusing as-designed and as-inspected data using knowledge graphs. Adv. Eng. Inform. 2020, 46, 101102. [CrossRef]

219. Ramnath, S.; Haghighi, P.; Venkiteswaran, A.; Shah, J.J. Interoperability of CAD geometry and product manufacturing information for computer integrated manufacturing. Int. J. Comput. Integr. Manuf. 2020, 33, 116-132. [CrossRef]

220. Liu, C.; Le Roux, L.; Körner, C.; Tabaste, O.; Lacan, F.; Bigot, S. Digital Twin-enabled Collaborative Data Management for Metal Additive Manufacturing Systems. J. Manuf. Syst. 2020. [CrossRef] 
221. Bonnard, R.; Hascoët, J.Y.; Mognol, P.; Zancul, E.; Alvares, A.J. Hierarchical object-oriented model (HOOM) for additive manufacturing digital thread. J. Manuf. Syst. 2019, 50, 36-52. [CrossRef]

222. Ganser, P.; Landwehr, M.; Schiller, S.; Vahl, C.; Mayer, S.; Bergs, T. Knowledge-Based Adaptation of Product and Process Design in Blisk Manufacturing. J. Eng. Gas Turbines Power 2021. [CrossRef]

223. Zhang, L.; Chen, X.; Zhou, W.; Cheng, T.; Chen, L.; Guo, Z.; Han, B.; Lu, L. Digital twins for additive manufacturing: A state-of-the-art review. Appl. Sci. 2020, 10, 8350. [CrossRef]

224. Dittrich, M.A.; Schleich, B.; Clausmeyer, T.; Damgrave, R.; Erkoyuncu, J.A.; Haefner, B.; de Lange, J.; Plakhotnik, D.; Scheidel, W.; Wuest, T. Shifting value stream patterns along the product lifecycle with digital twins. Procedia CIRP 2020, 86, 3-11. [CrossRef]

225. Wagner, R.; Schleich, B.; Haefner, B.; Kuhnle, A.; Wartzack, S.; Lanza, G. Challenges and potentials of digital twins and industry 4.0 in product design and production for high performance products. Procedia CIRP 2019, 84, 88-93. [CrossRef]

226. Schuh, G.; Stich, V.; Basse, F.; Franzkoch, B.; Harzenetter, F.; Luckert, M.; Prote, J.; Reschke, J.; Schmitz, S.; Tücks, G.; et al. Change request im Produktionsbetrieb. In AWK Aachener Werkzeugmaschinen-Kolloquium; Apprimus Verlag: Aachen, Germany, 2017; pp. 109-131.

227. Shen, Y.; Guo, D.; Long, F.; Mateos, L.A.; Ding, H.; Xiu, Z.; Hellman, R.B.; King, A.; Chen, S.; Zhang, C.; et al. Robots Under COVID-19 Pandemic: A Comprehensive Survey. IEEE Access 2020, 9, 1590-1615. [CrossRef]

228. Cichon, T.; Rosmann, J. Robotic teleoperation: Mediated and supported by virtual testbeds. In Proceedings of the 2017 IEEE International Symposium on Safety, Security and Rescue Robotics (SSRR), Shanghai, China, 11-13 October 2017; pp. 55-60. [CrossRef]

229. Pairet, E.; Ardón, P.; Liu, X.; Lopes, J.; Hastie, H.; Lohan, K.S. A Digital Twin for Human-Robot Interaction. In Proceedings of the ACM/IEEE International Conference on Human-Robot Interaction, Daegu, Korea, 11-14 March 2019; p. 372. [CrossRef]

230. Malik, A.A.; Brem, A. Man, machine and work in a digital twin setup: A case study. arXiv 2020, arXiv:2006.08760.

231. Joseph, A.J.; Kruger, K.; Basson, A.H. An Aggregated Digital Twin Solution for Human-Robot Collaboration in Industry 4.0 Environments; Springer International Publishing: Cham, Switzerland, 2021; pp. 135-147._9. [CrossRef]

232. KUTS, V.; CHEREZOVA, N.; SARKANS, M.; OTTO, T. Digital Twin: Industrial robot kinematic model integration to the virtual reality environment. J. Mach. Eng. 2020, 20, 53-64. [CrossRef]

233. Liang, C.J.; McGee, W.; Menassa, C.; Kamat, V. Bi-Directional Communication Bridge for State Synchronization between Digital Twin Simulations and Physical Construction Robots. In Proceedings of the 37th International Symposium on Automation and Robotics in Construction (ISARC), Kitakyushu, Japan, 26-30 October 2020,

234. Girletti, L.; Groshev, M.; Guimaraes, C.; Bernardos, C.J.; de la Oliva, A. An Intelligent Edge-based Digital Twin for Robotics. In Proceedings of the 2020 IEEE Globecom Workshops (GC Wkshps), Taipei, Taiwan, 7-11 December 2020; pp. 1-6. [CrossRef]

235. Kuts, V.; Sarkans, M.; Otto, T.; Tähemaa, T.; Bondarenko, Y. Digital Twin: Concept of Hybrid Programming for Industrial Robots-Use Case. In Procedings of the ASME 2019 International Mechanical Engineering Congress and Exposition, Salt Lake City, UT, USA, 11-14 November 2019. [CrossRef]

236. Li, L.; Xu, W.; Liu, Z.; Yao, B.; Zhou, Z.; Pham, D.T. Digital twin-based control approach for industrial cloud robotics. In Processing of the ASME 2019 14th International Manufacturing Science and Engineering Conference, Erie, PA, USA, 10-14 June 2019; Voluem 1, pp. 1-7. [CrossRef]

237. Xu, W.; Cui, J.; Li, L.; Yao, B.; Tian, S.; Zhou, Z. Digital twin-based industrial cloud robotics: Framework, control approach and implementation. J. Manuf. Syst. 2020. [CrossRef]

238. Larsen, C. Including a Collaborative Robot in Digital Twin Manufacturing Systems. Master's Thesis, Chalmers University of Technology, Gothenburg, Sweden, 2019.

239. Yan, K.; Xu, W.; Yao, B.; Zhou, Z.; Pham, D.T. Digital Twin-Based Energy Modeling of Industrial Robots; Springer: Singapore, 2018; Volume 946, pp. 333-348._26. [CrossRef]

240. MPOC. Digital Twin Methods for Feedback Control in Multi-Robot Welding Cells. 2020. Available online: https://lutpub.lut.fi/ handle/10024/160848 (accessed on 21 September 2020).

241. Burghardt, A.; Szybicki, D.; Gierlak, P.; Kurc, K.; Pietruś, P.; Cygan, R. Programming of industrial robots using virtual reality and digital twins. Appl. Sci. 2020, 10, 486. [CrossRef]

242. Tipary, B.; Erdős, G. Generic development methodology for flexible robotic pick-and-place workcells based on Digital Twin. Robot. Comput.-Integr. Manuf. 2021, 71, 102140. [CrossRef]

243. Hoebert, T.; Lepuschitz, W.; List, E.; Merdan, M. Cloud-Based Digital Twin for Industrial Robotics. In Proceedings of the International Conference on Industrial Applications of Holonic and Multi-Agent Systems, Linz, Austria, 26-29 August 2019; Springer: Berlin/Heidelberg, Germany, 2019; Volume 11710 LNAI, pp. 105-116._9. [CrossRef]

244. Kousi, N.; Gkournelos, C.; Aivaliotis, S.; Giannoulis, C.; Michalos, G.; Makris, S. Digital twin for adaptation of robots' behavior in flexible robotic assembly lines. Procedia Manuf. 2019, 28, 121-126. [CrossRef]

245. Meng, S.; Tang, S.; Zhu, Y.; Chen, C. Digital Twin-Driven Control Method for Robotic Automatic Assembly System. IOP Conf. Ser. Mater. Sci. Eng. 2019, 493, 012128. [CrossRef]

246. Pérez, L.; Rodríguez-Jiménez, S.; Rodríguez, N.; Usamentiaga, R.; García, D.F. Digital twin and virtual reality based methodology for multi-robot manufacturing cell commissioning. Appl. Sci. 2020, 10, 3633. [CrossRef]

247. He, B.; Cao, X.; Hua, Y. Data fusion-based sustainable digital twin system of intelligent detection robotics. J. Clean. Prod. 2021, 280, 124181. [CrossRef] 
248. Fedotov, A.A.; Sergeev, S.M.; Provotorova, E.N.; Prozhogina, T.V.; Zaslavskaya, O.Y. The digital twin of a warehouse robot for Industry 4.0. IOP Conf. Ser. Mater. Sci. Eng. 2020, 862, 032061. [CrossRef]

249. Filocamo, C. Digital Twin and HMI for Collaborative Autonomous Mobile Robots in Flexible Logistics. Ph.D. Thesis, Politecnico di Torino, Torino, Italy, 2020.

250. Franko, J.; Du, S.; Kallweit, S.; Duelberg, E.; Engemann, H. Design of a multi-robot system for wind turbine maintenance. Energies 2020, 13, 2552. [CrossRef]

251. Cai, B.; Du, H.; Cong, Y.; Xie, F.; Zhang, J. Research on Angle Steel Tower Climbing Robot System Based on Digital Twin. In Proceedings of the 20207 th International Conference on Information, Cybernetics, and Computational Social Systems (ICCSS), Guangzhou, China, 13-15 November 2020; pp. 749-754. [CrossRef]

252. Agüero, C.E.; Koenig, N.; Chen, I.; Boyer, H.; Peters, S.; Hsu, J.; Gerkey, B.; Paepcke, S.; Rivero, J.L.; Manzo, J.; et al. Inside the Virtual Robotics Challenge: Simulating Real-Time Robotic Disaster Response. IEEE Trans. Autom. Sci. Eng. 2015, 12, 494-506. [CrossRef]

253. Todorov, E.; Erez, T.; Tassa, Y. MuJoCo: A physics engine for model-based control. IEEE Int. Conf. Intell. Robot. Syst. 2012, 5026-5033. [CrossRef]

254. Rohmer, E.; Singh, S.P.; Freese, M. V-REP: A versatile and scalable robot simulation framework. IEEE Int. Conf. Intell. Robot. Syst. 2013, 1321-1326. [CrossRef]

255. Maschler, B.; Braun, D.; Jazdi, N.; Weyrich, M. Transfer Learning as an Enabler of the Intelligent Digital Twin. Procedia CIRP 2020, 100, 2-7. [CrossRef]

256. Verner, I.M.; Cuperman, D.; Reitman, M. Robot online learning to lift weights: A way to expose students to robotics and intelligent technologies. Int. J. Online Eng. 2017, 13, 174-182. [CrossRef]

257. Liang, C.J.; Kamat, V.R.; Menassa, C.C. Teaching robots to perform construction tasks via learning from demonstration. In Proceedings of the 36th International Symposium on Automation and Robotics in Construction, ISARC 2019, Banff, AB, Canada, 21-24 May 2019; pp. 1305-1311. [CrossRef]

258. Yu, J.; Yuan, J.; Wu, Z.; Tan, M. Data-Driven Dynamic Modeling for a Swimming Robotic Fish. IEEE Trans. Ind. Electron. 2016, 63, 5632-5640. [CrossRef]

259. Glabeke, T.; Kehrer, C.; Bromberger, M. Digital Twin Design Process for Efficient Development and Operation of a Customized Robot. Technical Report. 2020. Available online: https://www.altair.com/resource/digital-twin-design-process-for-efficientdevelopment-and-operation-of-a-customized-robot (accessed on 21 September 2021).

260. Jin, T.; Sun, Z.; Li, L.; Zhang, Q.; Zhu, M.; Zhang, Z.; Yuan, G.; Chen, T.; Tian, Y.; Hou, X.; et al. Triboelectric nanogenerator sensors for soft robotics aiming at digital twin applications. Nat. Commun. 2020, 11, 1-12. [CrossRef] [PubMed]

261. Verner, I.; Cuperman, D.; Fang, A.; Reitman, M.; Romm, T.; Balikin, G. Robot online learning through digital twin experiments: A weightlifting project. Lect. Notes Netw. Syst. 2018, 22, 307-314._29. [CrossRef]

262. Vrabič, R.; Erkoyuncu, J.A.; Butala, P.; Roy, R. Digital twins: Understanding the added value of integrated models for through-life engineering services. Procedia Manuf. 2018, 16, 139-146. [CrossRef]

263. Oyekan, J.; Farnsworth, M.; Hutabarat, W.; Miller, D.; Tiwari, A. Applying a 6 dof robotic arm and digital twin to automate fan-blade reconditioning for aerospace maintenance, repair, and overhaul. Sensors 2020, 20, 4637. [CrossRef] [PubMed]

264. Klamt, T.; Kamedula, M.; Karaoguz, H.; Kashiri, N.; Laurenzi, A.; Lenz, C.; Leonardis, D.; Mingo Hoffman, E.; Muratore, L.; Pavlichenko, D.; et al. Flexible Disaster Response of Tomorrow: Final Presentation and Evaluation of the CENTAURO System. IEEE Robot. Autom. Mag. 2019, 26, 59-72. [CrossRef]

265. Matulis, M.; Harvey, C. A robot arm digital twin utilising reinforcement learning. Comput. Graph. 2021, 95, 106-114. [CrossRef]

266. Liu, C.; Gao, J.; Bi, Y.; Shi, X.; Tian, D. A Multitasking-Oriented Robot Arm Motion Planning Scheme Based on Deep Reinforcement Learning and Twin Synchro-Control. Sensors 2020, 20, 3515. [CrossRef]

267. Xia, K.; Sacco, C.; Kirkpatrick, M.; Saidy, C.; Nguyen, L.; Kircaliali, A.; Harik, R. A digital twin to train deep reinforcement learning agent for smart manufacturing plants: Environment, interfaces and intelligence. J. Manuf. Syst. 2020, 58, 210-230. [CrossRef]

268. Zhao, Y.; Guo, J.; Bai, C.; Zheng, H. Reinforcement Learning-Based Collision Avoidance Guidance Algorithm for Fixed-Wing UAVs. Complexity 2021, 2021, 8818013. [CrossRef]

269. Bansal, R.; Khanesar, M.A.; Branson, D. Ant colony optimization algorithm for industrial robot programming in a digital twin. In Proceedings of the 2019 25th International Conference on Automation and Computing (ICAC), Lancaster, UK, 5-7 September 2019; pp. 5-7. [CrossRef]

270. Li, G.; Liu, Z.; Cai, L.; Yan, J. Standing-Posture Recognition in Human-Robot Collaboration Based on Deep Learning and the Dempster-Shafer Evidence Theory. Sensors 2020, 20, 1158. [CrossRef] [PubMed]

271. Cichon, T.; Robmann, J. Digital Twins: Assisting and Supporting Cooperation in Human-Robot Teams. In Proceedings of the 2018 15th International Conference on Control, Automation, Robotics and Vision (ICARCV), Singapore, 18-21 November 2018; pp. 486-491. [CrossRef]

272. Dröder, K.; Bobka, P.; Germann, T.; Gabriel, F.; Dietrich, F. A machine learning-enhanced digital twin approach for human-robotcollaboration. Procedia CIRP 2018, 76, 187-192. [CrossRef]

273. Wang, T.; Li, J.; Kong, Z.; Liu, X.; Snoussi, H.; Lv, H. Digital twin improved via visual question answering for vision-language interactive mode in human-machine collaboration. J. Manuf. Syst. 2020. [CrossRef] 
274. Wang, Q.; Jiao, W.; Wang, P.; Zhang, Y. Digital Twin for Human-Robot Interactive Welding and Welder Behavior Analysis. IEEE/CAA J. Autom. Sin. 2021, 8, 334-343. [CrossRef]

275. Lv, Q.; Zhang, R.; Sun, X.; Lu, Y.; Bao, J. A digital twin-driven human-robot collaborative assembly approach in the wake of COVID-19. J. Manuf. Syst. 2021. [CrossRef]

276. Anton, F.; Borangiu, T.; Răileanu, S.; Anton, S. Cloud-Based Digital Twin for Robot Integration in Intelligent Manufacturing Systems. Mech. Mach. Sci. 2020, 84, 565-573._60. [CrossRef]

277. Aivaliotis, P.; Arkouli, Z.; Georgoulias, K.; Makris, S. Degradation curves integration in physics-based models: Towards the predictive maintenance of industrial robots. Robot. Comput.-Integr. Manuf. 2021, 71, 102177. [CrossRef]

278. He, B.; Zhu, X.; Zhang, D. Boundary encryption-based Monte Carlo learning method for workspace modeling. J. Comput. Inf. Sci. Eng. 2020, 20, 1-6. [CrossRef]

279. Zushida, K.; Haohao, Z.; Shimamura, H.; Motegi, K.; Shiraishi, Y. Estimation of Lawn Grass Lengths based on Random Forest Algorithm for Robotic Lawn Mower. In Proceedings of the 2020 59th Annual Conference of the Society of Instrument and Control Engineers of Japan, SICE 2020, Chiang Mai, Thailand, 23-26 September 2020; pp. 1628-1633.

280. Kapusta, A.; Yu, W.; Bhattacharjee, T.; Liu, C.K.; Turk, G.; Kemp, C.C. Data-driven haptic perception for robot-assisted dressing. In Proceedings of the 25th IEEE International Symposium on Robot and Human Interactive Communication, RO-MAN 2016, New York, NY, USA, 26-31 August 2016, pp. 451-458. [CrossRef]

281. Piacenza, P.; Behrman, K.; Schifferer, B.; Kymissis, I.; Ciocarlie, M. A Sensorized Multicurved Robot Finger with Data-Driven Touch Sensing via Overlapping Light Signals. IEEE/ASME Trans. Mechatronics 2020, 25, 2416-2427. [CrossRef]

282. Santina, C.D.; Truby, R.L.; Rus, D. Data-Driven Disturbance Observers for Estimating External Forces on Soft Robots. IEEE Robot. Autom. Lett. 2020, 5, 5717-5724. [CrossRef]

283. Grinshpun, G.; Cichon, T.; Dipika, D.; Rossmann, J. From virtual testbeds to real lightweight robots: Development and deployment of control algorithms for soft robots, with particular reference to industrial peg-in-hole insertion tasks. In Proceedings of the ISR 2016: 47st International Symposium on Robotics, Munich, Germany, 21-22 June 2016; pp. 208-214.

284. Reinhart, R.F.; Shareef, Z.; Steil, J.J. Hybrid analytical and data-driven modeling for feed-forward robot controlt. Sensors 2017, 17, 311. [CrossRef] [PubMed]

285. Lyu, S.; Cheah, C.C. Data-driven learning for robot control with unknown Jacobian. Automatica 2020, 120, 109120. [CrossRef]

286. Frank, M.; Leitner, J.; Stollenga, M.; Forster, A.; Schmidhuber, J. Curiosity driven reinforcement learning for motion planning on humanoids. Front. Neurorobotics 2014, 7, 1-15. [CrossRef]

287. Bengio, Y.; Courville, A.; Vincent, P. Representation Learning: A Review and New Perspectives. IEEE Trans. Pattern Anal. Mach. Intell. 2013, 35, 1798-1828. [CrossRef]

288. System Understanding with Digital Twins-Increasing Performance without Compromising Quality or Robustness. Available online: https:/ / web.altair.com/en/mechatronic_digital-twin-design-process-for-robot-customization (accessed on 21 September 2021).

289. Bilberg, A.; Malik, A.A. Digital twin driven human-robot collaborative assembly. CIRP Ann. 2019, 68, 499-502. [CrossRef]

290. Malik, A.A.; Brem, A. Digital twins for collaborative robots: A case study in human-robot interaction. Robot. Comput.-Integr. Manuf. 2021, 68, 102092. [CrossRef]

291. Admoni, H.; Scassellati, B. Data-driven model of nonverbal behavior for socially assistive human-robot interactions. In Proceedings of the 16th international conference on multimodal interaction, Istanbul, Turkey, 12-16 November 2014; pp. 196-199. [CrossRef]

292. Wang, X.; Liang, C.J.; Menassa, C.; Kamat, V. Real-Time Process-Level Digital Twin for Collaborative Human-Robot Construction Work. In Proceedings of the 37th International Symposium on Automation and Robotics in Construction (ISARC), Kitakyushu, Japan, 28 October 2020. [CrossRef]

293. Khalastchi, E.; Kalech, M.; Kaminka, G.A.; Lin, R. Online data-driven anomaly detection in autonomous robots. Knowl. Inf. Syst. 2015, 43, 657-688. [CrossRef]

294. Vallachira, S.; Orkisz, M.; Norrlof, M.; Butail, S. Data-driven gearbox failure detection in industrial robots. IEEE Trans. Ind. Inform. 2020, 16, 193-201. [CrossRef]

295. Schluse, M.; Rossmann, J. From Simulation to Experimentable Digital Twins. In Proceedings of the IEEE International Symposium on Systems Engineering, Edinburgh, UK, 3-5 October 2016; pp. 1-6.

296. Stehling, M.; Schmiedinger, T.; Affenzeller, P. Why Robots do not matter! Using Digital Twin and Augmented Learning for Continuous Improvement in the context of Manufacturing. Researchgate.Net. 2017. Available online: https: / / www.researchgate.net/publication/329218023_Why_Robots_do_not_matter_Using_Digital_Twin_and_Augmented_ Learning_for_Continuous_Improvement_in_the_context_of_Manufacturing (accessed on 21 September 2021).

297. Verner, I.; Cuperman, D.; Gamer, S.; Polishuk, A. Training robot manipulation skills through practice with digital twin of Baxter. Int. J. Online Biomed. Eng. 2019, 15, 58-70. [CrossRef]

298. Verner, I.; Cuperman, D.; Gamer, S.; Polishuk, A. Digital Twin of the Robot Baxter for Learning Practice in Spatial Manipulation Tasks; Springer International Publishing: Cham, Switzerland, 2020; Volume 80, pp. 81-92. [CrossRef]

299. Havard, V.; Jeanne, B.; Lacomblez, M.; Baudry, D. Digital twin and virtual reality: A co-simulation environment for design and assessment of industrial workstations. Prod. Manuf. Res. 2019, 7, 472-489. [CrossRef] 
300. Rückert, P.; Tracht, K.; Herfs, W.; Roggendorf, S.; Schubert, V.; Schneider, M. Consolidation of product lifecycle information within human-robot collaboration for assembly of multi-variant products. Procedia Manuf. 2020, 49, 217-221. [CrossRef]

301. Boos, W.; Kelzenberg, C.; Helbig, J.; Busch, M.; Graberg, T.; Schweins, J. Wettbewerbsfaktor Nachhaltigkeit: Ein Differenzierungsmerkmal für den Werkzeugbau. 2020. Available online: https://studien.werkzeugbau-akademie.de/de/unsere_ studien/ (accessed on 13 September 2021). 